\title{
Toxoplasma-proximal and distal control by GBPs in human macrophages
}

\author{
Daniel Fisch ${ }^{1,2}$, Barbara Clough ${ }^{1,2}$, Rabia Khan $^{2}$, Lyn Healy ${ }^{3}$, Eva-Maria Frickel ${ }^{1,2}$ \\ ${ }^{1}$ Institute of Microbiology and Infection, School of Biosciences, University of Birmingham, Edgbaston B15 2TT, UK \\ ${ }^{2}$ Host-Toxoplasma Interaction Laboratory, The Francis Crick Institute, London NW1 1AT, UK \\ ${ }^{3}$ HESCU (Human Embryo and Stem Cell Unit), The Francis Crick Institute, London NW1 1AT, UK
}

\begin{abstract}
Human guanylate-binding proteins (GBPs) are key players of interferon-gamma (IFNy)-induced cell intrinsic defense mechanisms targeting intracellular pathogens. In this study we combine the well-established Toxoplasma gondii infection model with three in vitro macrophage culture systems to delineate the contribution of individual GBP family members to control this apicomplexan parasite. Use of high-throughput imaging assays and genome engineering allowed us to define a role for GBP1, 2 and 5 in parasite infection control. While GBP1 performs a pathogen-proximal, parasiticidal and growth-restricting function through accumulation at the parasitophorous vacuole of intracellular Toxoplasma, GBP2 and 5 perform a pathogen-distal, growth-restricting role. We further find that mutants of the GTPase or isoprenylation site of GBP1/2/5 affect their normal function in Toxoplasma control by leading to mis-localization of the proteins.
\end{abstract}

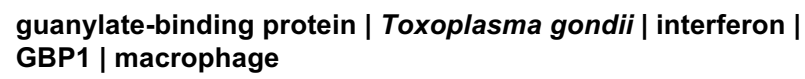

Correspondence: e.frickel@bham.ac.uk

\section{INTRODUCTION}

Human cells can defend themselves against pathogens in a process known as cell-intrinsic immunity (MacMicking 2012). Many proteins participating in this are induced by cytokine signaling such as signaling mediated by exposure to the type II interferon-gamma (IFNy) (Ivashkiv 2018). Amongst IFNy-induced proteins are several classes of immune GTPases, including the $63 \mathrm{kDa}$ guanylate-binding proteins (GBPs). Humans possess seven GBP genes (GBP1-7) located in a cluster on chromosome 1 (Olszewski, Gray and Vestal 2006). All GBPs have a similar structure with a $\mathrm{N}$-terminal globular GTPase domain and an elongated C-terminal helical domain (Prakash et al. 2000). The GTPase hydrolyses GTP to GDP which induces conformational changes of the proteins (Ghosh et al. 2006; Barz, Loschwitz and Strodel 2019; Ince et al. 2020). Furthermore, some GBP family members can also hydrolyze GDP to GMP, a unique feature of these proteins (Schwemmle and Staeheli 1994; Praefcke et al. 2004; Abdullah, Balakumari and Sau 2010; Wehner and Herrmann 2010). The human GBPs 1,2 and 5 have a CaaX-box at their C-terminus, which can be modified with an isoprenyl anchor. This lipid tail, together with other sites of the proteins, e.g. a C-terminal polybasic motif R584-586 (Kohler et al. 2020), allows for membrane interaction. Moreover, GBPs are known to form dimers and homo-/heterooligomers as well as larger protein aggregates (BritzenLaurent et al. 2010; Kravets et al. 2016; Ince et al. 2017; Wandel et al. 2017; Kutsch et al. 2020). Some family members are known to target cytosolic and vacuolar bacterial, viral, or protozoal pathogens within cells which leads to their disruption and exposure (Tretina et al. 2019). Other functions of GBPs include modulation of apoptosis and pyroptosis, cytokine production, autophagy, radical production, and energy metabolism (Tretina et al. 2019). Altogether, they contribute to efficient control of intracellular pathogens.

One common intracellular pathogen of humans is the apicomplexan parasite Toxoplasma gondii $(\mathrm{Tg})$, with roughly $30 \%$ of humans suffering from non-symptomatic, persistent infection (Pappas, Roussos and Falagas 2009). Tg grows intracellularly once it has infected a human host, forming its own subcellular compartment known as the parasitophorous vacuole (PV) (Sibley 2011). Within the PV, Tg is protected from detection by cytosolic pattern recognition receptors and the innate immune system (Clough and Frickel 2017). While asymptomatic in immune-competent hosts, where $\mathrm{Tg}$ transforms into a dormant infection forming tissue cysts in brain and muscle, the parasite can cause the disease known as toxoplasmosis in immunocompromised individuals. Moreover, recurring ocular infections with $\mathrm{Tg}$ are a common morbidity in South America, as are complications upon new infection with $\mathrm{Tg}$ during pregnancy (Desmonts et al. 1985; Daffos et al. 1988; Remington et al. 2011). Tg infection control in humans critically depends a cell-mediated immune response and on the cytokine IFNy (Gazzinelli et al. 1993, 1994; Hunter et al. 1994; Wilson, Matthews and Yap 2008). $\mathrm{Tg}$ is therefore a good model pathogen to assess the function of human GBPs. 
A
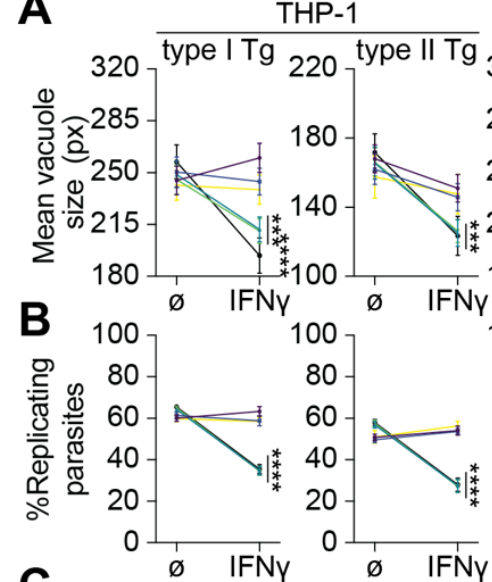

C
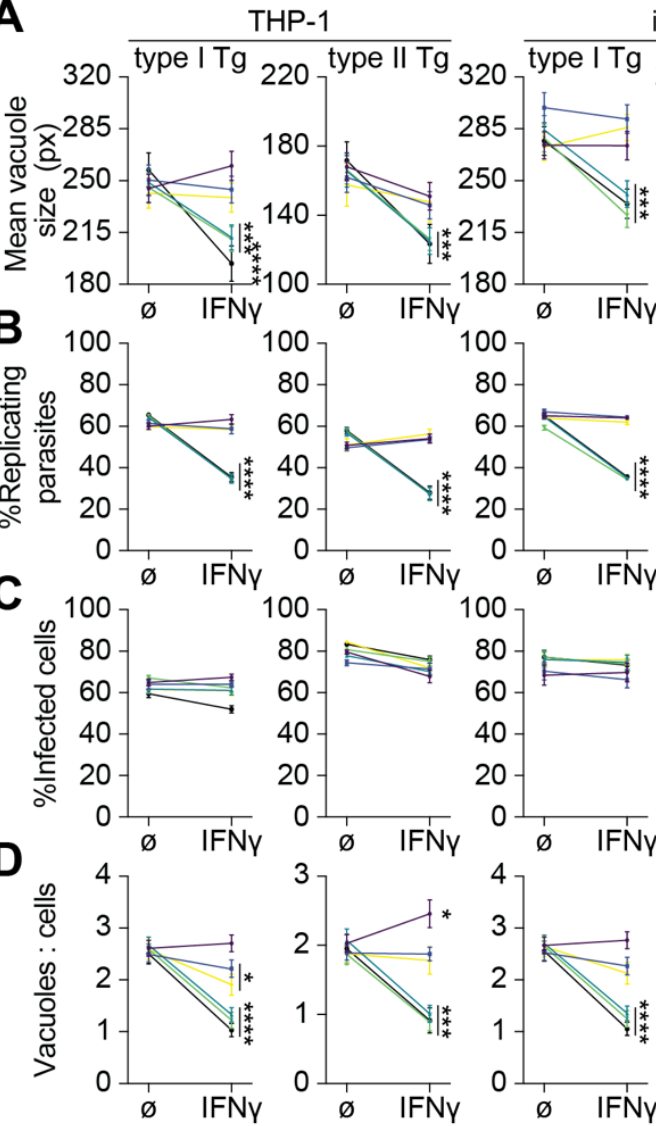

iPSC

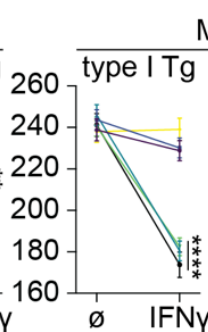

MDMs
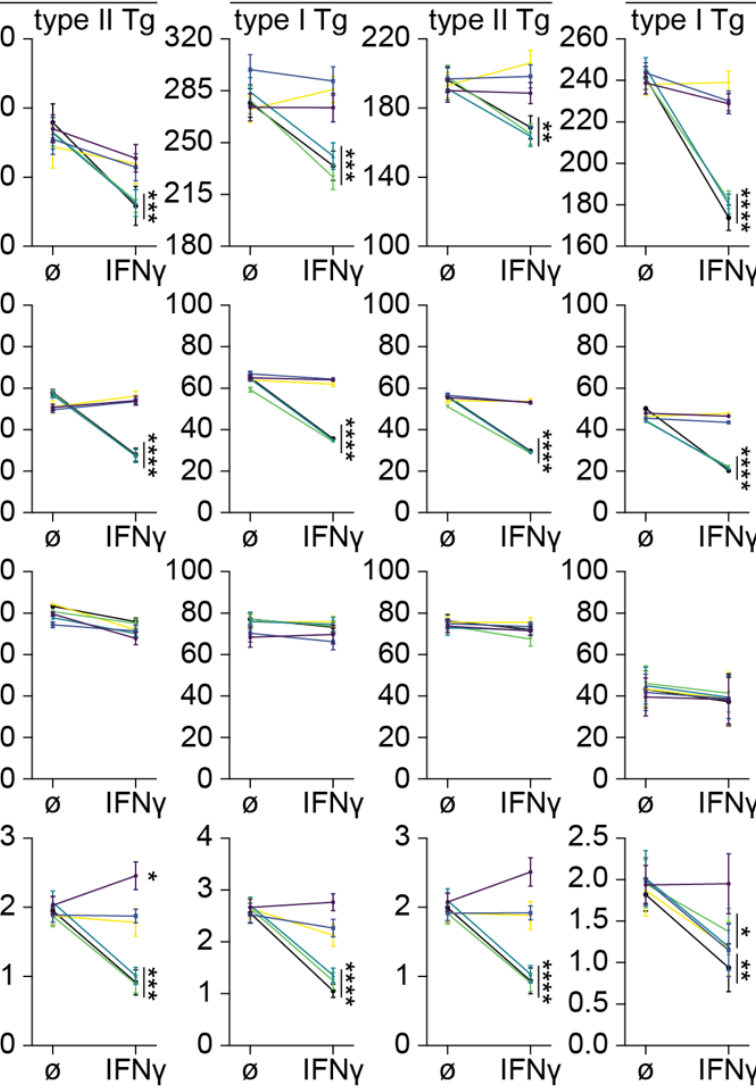

E
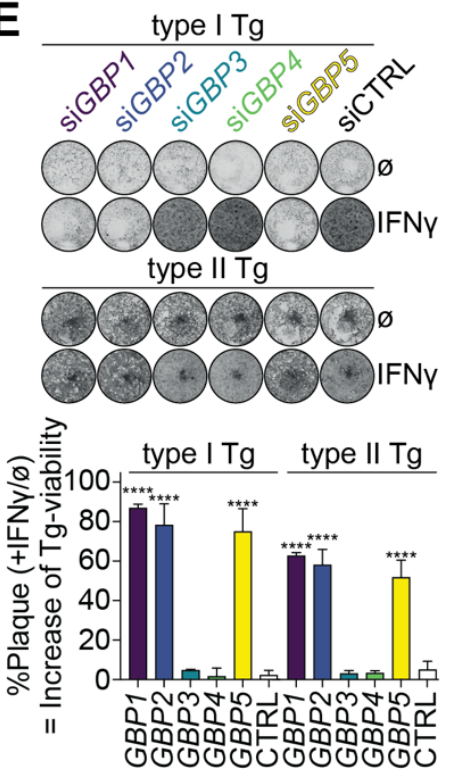

SiRNA

Figure 1: Selective human GBPs limit Toxoplasma parasite numbers and restrict their growth in human macrophages HRMAn-based quantification of mean vacuole size (A), proportion of replicating parasites (B), proportion of infected cells (C) and ratio between vacuoles and cells (D) of THP-1, induced pluripotent stem cell (iPSC)-derived or monocyte-derived macrophages (MDM) transfected with siRNA against the indicated GBP or non-targeting control (CTRL), untreated or primed with IFNy and infected with type I (RH) or type II (PRU) Toxoplasma gondii (Tg) at 18 hours p.i. (E) Images of HFF plaques formed by Tg obtained following growth in naïve or IFNy-primed THP-1 cells for 18 hours additionally transfected with siRNAs against the indicated GBP or CTRL (top) and quantification of plaque area from images (bottom). Plaque area of Tg normalized to the corresponding naïve condition, to represent the increase of Tg-viability caused by silencing of the respective GBP. Data information: Graphs in (A-D) shown mean \pm SEM from $n=3$ independent experiments or $n=4$ donors (MDMs). Images in (E) representative of $n=3$ independent experiments. ${ }^{*} P \leq 0.05$; ${ }^{* *} P \leq 0.01$; ${ }^{* * *} P \leq 0.001 ;{ }^{* * * *} P \leq 0.0001$ in (A-D) from two-way ANOVA comparing unprimed to IFNY-primed condition and in (E) comparing to CTRL siRNA transfected cells following adjustment for multiple comparisons.

Macrophages are key cells of the innate immune system. They derive from monocytes infiltrating an inflamed/infected tissue and serve several purposes: macrophages (1) actively phagocytose pathogens and reduce the infectious burden (Rosales and Uribe-Querol 2017), (2) produce cytokines that prime the immune response (Wynn, Chawla and Pollard 2013), (3) present antigens for activation of the adaptive immune response (Roche and Furuta 2015; Hughes et al. 2016), (4) clear debris from dead cells (Green, Oguin and Martinez 2016) and (5) contribute to healing of damaged tissues (Feghali and Wright 1997; Cronkite and Strutt 2018). IFNy which is produced in large amounts during a cell-mediated immune response (Dinarello 2007; Turner et al. 2014), activates and polarizes macrophages, and is the key inducer-cytokine for GBPs (Cheng et al. 1985; Darnell, Kerr and Stark 1994; Boehm et al. 1998). Therefore, GBP-expressing macrophages frequently encounter $\mathrm{Tg}$ and are a well-suited model cell line to study GBP functions with sufficient physiological relevance.
Several model cell lines and systems are used to study macrophage biology. One of the most used is the monocytic cancer cell line THP-1 (Chanput, Mes and Wichers 2014). Since long-term culture induces unwanted genetic drift, culture of THP-1 is usually restricted to fewer passages. THP-1 monocytes can be terminally differentiated using phorbol 12-myristate 13-acetate (PMA), a small molecule, irreversible activator of PKC (Ryves et al. 1991). Hence, PMA needs to be employed at the minimal concentration necessary for differentiation, in order to reduce activation of cells and so avoid masking any effects of further activations (Park et al. 2007). Use of THP-1 cells allows for genome-editing but has the disadvantage of using immortalized cells. Newer systems instead use induced pluripotent stem cells (iPSC). The KOLF iPS cell line can be maintained in culture indefinitely and can be transformed into embryonic bodies (EBs), which upon addition of a cytokine cocktail work as monocyte production factories. Monocytes can be harvested weekly or fortnightly and then terminally differentiated 

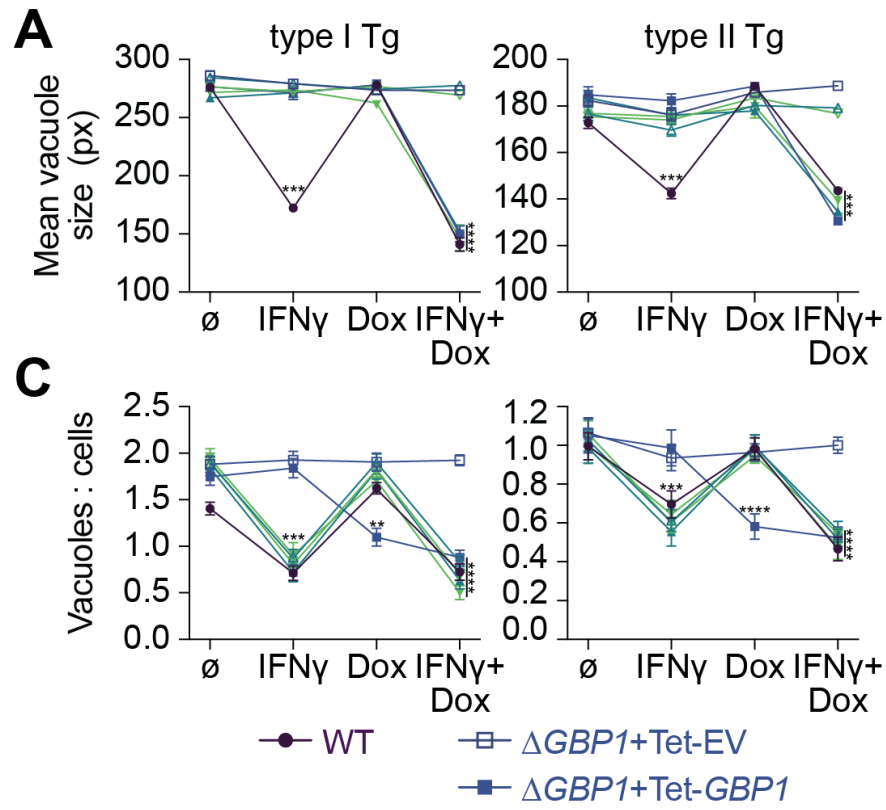

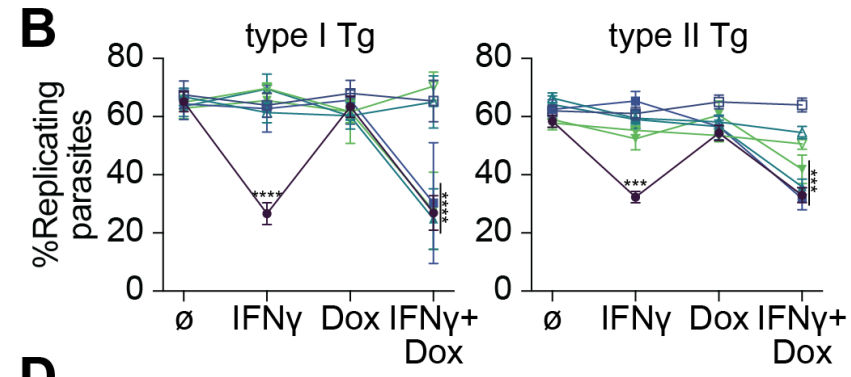

D

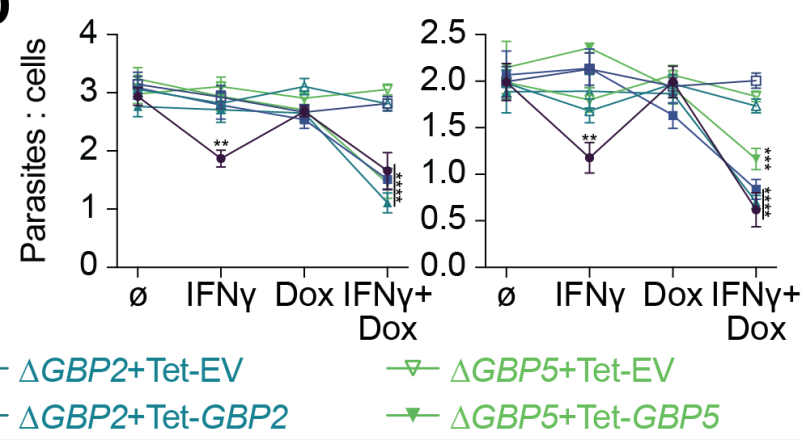

Figure 2: Re-expression of GBPs restores Toxoplasma restriction in $\triangle G B P$ cells

HRMAn-based quantification of mean vacuole size (A), proportion of replicating parasites (B), ratio between vacuoles and cells (C) and ratio between parasites and cells (D) of THP-1 $\triangle G B P 1, \triangle G B P 2$ or $\triangle G B P 5$ cells transduced with Tet-empty vector (EV, open symbols) or Tet-GBP1/2/5 (closed symbols) untreated or primed with IFNy and/or Doxycycline (Dox) and infected with type I (RH) or type II (PRU) Toxoplasma gondii (Tg) at 18 hours p.i. Data information: Graphs in (A-D) shown mean \pm SEM from $n=3$ independent experiments. ${ }^{*} P \leq 0.05 ;{ }^{* *} P \leq 0.01 ;{ }^{* * *} P \leq 0.001 ;{ }^{* * *} P \leq 0.0001$ for indicated condition in (A-D) from two-way ANOVA comparing to untreated condition following adjustment for multiple comparisons.

into macrophages with M-CSF (Wilgenburg et al. 2013). This produces primary-like human cells. Lastly, primary cells can be used for macrophage biology research. To obtain these, leukocytes are enriched from healthy donor blood. From this, peripheral blood mononuclear cells (PBMCs) can be purified by density-gradient centrifugation from which monocytes are isolated based on surface expression of CD14. These can be terminally differentiated into monocyte-derived macrophages (MDMs). Since MDMs are primary cells, they most accurately reflect human biology. Combining these systems allows for an optimal in vitro study of human macrophage biology (Tedesco et al. 2018).

In this study, we combine the three distinct macrophage models with gene silencing, genome engineering and high-throughput imaging to delineate the contribution of human GBPs and their mutants to control of $\mathrm{Tg}$ infection. We demonstrate that isoprenylated GBPs control the in-part uncoupled processes of $\mathrm{Tg}$ growth restriction and parasite killing, critically depending on their correct subcellular localization. Using panels of GBP mutants, we show that GTPase activity and isoprenylation dictate GBP localization and their pathogen-proximal and -distal roles in cell-intrinsic immunity.

\section{RESULTS}

Human GBP1, 2 and 5 restrict Toxoplasma growth in human macrophages and human GBP1 reduces Toxoplasma parasite vacuole numbers

To study the function of human GBPs in the context of controlling Tg infection, we utilized three distinct human macrophage culture systems: PMA-differentiated THP-1 macrophages, KOLF iPSCs and in vitro differentiated macrophages of purified primary $\mathrm{CD} 14^{+}$ monocytes from blood of healthy donors (Figure S1A). Flow cytometry analysis confirmed presence of the surface markers CD14, FcyRIII (CD16) and CD68 in all macrophage models (Figure S1B). RT-qPCR analysis of GBP expression after IFNy-treatment of the cells showed induction of expression for GBP1 through 5, but no expression of GBP6 or GBP7 in any of the three macrophage models (Figure S1C+D) (Fisch et al. 2019a). In all cells, GBP1 and GBP2 had the highest total expression levels, followed by GBP5 (Figures S1C). Interestingly, the non-isoprenylated GBPs 3 and 4 had the lowest total expression levels in all macrophage models (Figures S1C). Of all GBPs, GBP5 showed the highest IFNY-inducibility, which can be explained by the near complete absence of its transcript in naïve macrophages (Figure S1D). GBP3 consistently showed the lowest expression induction (Figure S1D).

Having confirmed expression of GBP1 through 5 following IFNy-treatment of human macrophages, we next used our previously established RNA interference assay, to specifically deplete cells of individual GBP transcripts (Fisch et al. 2019a) and assessed their influence on Tg-growth control using high-throughput imaging and analysis with HRMAn (Fisch et al. 2019b, 2021). With this assay we could establish that silencing of GBP1, GBP2 or GBP5 expression led to a loss of parasite growth restriction (Figure 1A) and replication restriction (Figure 1B) in all cell lines tested. No GBP appeared to have an influence on the overall proportion 
of infected cells (Figure 1C). Depletion of GBP1 additionally reduced the ability of all IFNy-primed macrophages to kill intracellular parasites, as measured by determining the vacuole:cell ratio, while GBP2 and 5 contributed to this function to a lesser extent in THP-1 and iPSC macrophages only (Figure 1D). Thus, we concluded that GBP1, 2 and 5-depletion significantly restricts $\mathrm{Tg}$ growth in 3 macrophage models, while GBP1 additionally kills $\mathrm{Tg}$ in all three macrophage models by reducing the vacuole/cell ratio.

To scrutinize these results obtained using our high-throughput imaging approach, we also determined $\mathrm{Tg}$ fitness with traditional plaque assays (Figure 1E). We could confirm our observation that GBP1, GBP2 and GBP5 exert Tg-growth control in IFNy-primed THP-1 macrophages (Figure 1E).

\section{Addition of IFNy is necessary for restoring Toxoplasma growth restriction, but not parasite vacuole numbers when re-expressing GBPs in knockout cells}

To further assess the influence of GBP1, 2 and 5 in controlling $\mathrm{Tg}$ infection in macrophages, we next assessed THP-1 CRISPR knockout cell lines of the respective gene. THP-1 $\triangle G B P 1$ and $\triangle G B P 5$ were previously published (Krapp et al. 2016; Fisch et al. 2019a) and $\triangle G B P 2$ cells were created using the LentiCRISPR-v2 system. All cell lines were characterized by immunoblotting (Figure S2A), RTqPCR (Figure S2B), genotyping PCRs (Figure S2C) and Sanger sequencing (Figure S2D+E) to confirm absence of the protein and no off-target effects on the other GBP family members. Of note, the knockout cells were created with different approaches, where the GBP1 gene has a major truncation, GBP2 is entirely deleted and GBP5 has nonsense mutations, all rendering the respective gene product absent (Figure S2). Next, we used our previously described Doxycycline (Dox)-inducible system (Fisch et al. 2019a) and reconstituted the knockout cells with the respective GBP family member (Figure S2F). Using these cells in our high-throughput imaging assay, we were able to replicate the previous observation of a loss of Tg-growth and replication restriction in the $\triangle G B P 1$, $\triangle G B P 2$ and $\triangle G B P 5$ cells which could be reversed by expression induction through addition of Dox (Figure 2A+B). Interestingly, addition of Dox alone (expression of just the single GBP) was not sufficient and additional IFNy-treatment was required (Figure 2A+B). This might indicate that several GBPs act in concert or that another IFNy-inducible factor is required. For parasite killing on the other hand, GBP1 expression alone through Dox-induction could reverse the loss of vacuole/cell control (Figure 2C). This effect, however, was only fully restored to wildtype levels upon the extra addition of IFNy (Figure 2C). Complete ablation of GBP2 and 5 by CRISPR in THP-1 macrophages in contrast to downregulation by siRNA showed that these two GBPs are in fact not able to kill Tg via control of the vacuole/cell ratio (Figure 1D and 2C). Using HRMAn we further assessed the overall effect of GBP1, 2 and 5 on the total parasite load per cell (Figure 2D). This measure combines replication-restriction and killing, and it was only reduced comparable to IFNy-primed THP-1 WT, if $\triangle G B P 1, \triangle G B P 2$ and $\triangle G B P 5$ cells were treated with IFN $\gamma+$ Dox. This again shows that for the overall control of the parasite burden GBP1 is essential for killing and growth restriction, whereas GBP2 and GBP5 were needed solely for growth restriction (Figure 2D). In summary, human macrophages express GBPs 1 through 5 upon IFNy-stimulation and GBP1, 2 and 5 all contribute to the growth control of the intracellular parasites, while GBP1 is additionally responsible for controlling vacuole/cell numbers.

\section{GTPase activity and lipidation of GBP1, 2 and 5 are essential for their anti-Toxoplasma activity}

We next created panels of mutants for GBP1, GBP2 and GBP5 targeting their GTPase activity, C-terminal lipidation, the polybasic motif in GBP1 and its dimerization capacity (Figure 3A). We transduced the respective $\triangle G B P x$ cells with the Dox-inducible system (Figure S3). We then assessed the effect of these mutants on the functionality of the proteins (Figure 3B-D). To do so, we performed our highthroughput imaging assay as before by treating THP-1 macrophages with IFNY+Dox and normalized the resulting effects to the IFNY-only treated control of the same cell line. In this way, the only difference is presence or absence of the wildtype or mutated GBP protein in otherwise IFNy-primed cells. Like this, we were able to calculate the proportion of Tg-growth restriction or killing of the respective GBP functionality relative to the absence of the same GBP (Figure 3B-D).

Screening the GBP1 mutants showed that mutations rendering the GTPase activity non-functional (K51A, R48A, T75A, D184N or S52N) failed to restrict Tg growth and killing, whereas GTPase-mutants that predominantly affected GMP-production (E99A, D112A or D103L/D108L) still restricted the growth but failed to kill Tg. GBP1 $1^{\text {R4P }}$ with a predicted inactive GTPase was still active to restrict and kill $\mathrm{Tg}$, although slightly impaired in this capacity (Figure 3B). Isoprenylation site mutations (C589A or $4589-592)$ also failed to kill and restrict Tg-growth (Figure 3B).

GBP2 and GBP5 mutations that abolish GTP hydrolysis (K51A or D103L/D108L for GBP2 and KS51/52AA for GBP5) or mutations of the isoprenylation sites (C588A or $\triangle 588-591$ for both) failed to restrict Tg-growth (Figure 3C+D). Since neither protein contributes to Tg-killing, this was unaffected and likely carried out by endogenous GBP1 induced through IFNY-priming of the cells (Figure $3 C+D$ ). 
A

\begin{tabular}{|c|c|c|c|c|c|c|}
\hline & \multirow{2}{*}{\begin{tabular}{|l} 
Hydrolysis \\
IWT
\end{tabular}} & \multirow{2}{*}{$\begin{array}{c}\text { GTP } \\
? \\
-\end{array}$} & \multirow{2}{*}{\begin{tabular}{|c|} 
GDP \\
$?$ \\
- \\
\end{tabular}} & \multirow[t]{2}{*}{ Effect } & \multirow[t]{2}{*}{ Source } \\
\hline & & & & & & \\
\hline \multirow{13}{*}{$\frac{\Sigma}{0}$} & R48A & $0.85 \%$ & - & - & \multirow{3}{*}{ GTPase dead } & \multirow{6}{*}{ Praefcke et al, 2004} \\
\hline & E99A & $6.63 \%$ & - & - & & \\
\hline & T75A & $0.06 \%$ & - & - & & \\
\hline & $\mathrm{D} 184 \mathrm{~N}$ & $23.15 \%$ & + & - & GTPase & \\
\hline & $\mathrm{D} 112 \mathrm{~A}$ & $15.78 \%$ & + & - & deficient & \\
\hline & S52N & $0.10 \%$ & - & - & GTPase dead & \\
\hline & R48P & $0.50 \%$ & - & - & & Modiano et al, 2005 \\
\hline & D103L/D108L & $?$ & + & - & No GMP prod. & Abdullah et al, 2010 \\
\hline & $\Delta 589-592$ & $100 \%$ & + & + & & \multirow{3}{*}{$\begin{array}{l}\text { Britzen-Laurent et al, } \\
2010\end{array}$} \\
\hline & C589A & $100 \%$ & + & + & isoprenylation & \\
\hline & RK227/228EE & $100 \%$ & + & + & Dimeric & \\
\hline & D192E & $100 \%$ & + & + & No cleavage & Naschberger et al, 2017 \\
\hline & R584-586A & $100 \%$ & + & + & polybasic motif & Piro et al, 2017 \\
\hline \multirow{4}{*}{ 离 } & K51A & $<0.05 \%$ & - & - & GTPase dead & \multirow{3}{*}{$\begin{array}{l}\text { Britzen-Laurent et al, } \\
\qquad 2010\end{array}$} \\
\hline & $\Delta 588-591$ & $100 \%$ & + & + & & \\
\hline & C588A & $100 \%$ & + & + & isoprenylation & \\
\hline & D103L/D108L & $?$ & + & - & No GMP prod. & Abdullah et al, 2010 \\
\hline \multirow{3}{*}{ 密. } & KS51/52AA & $<0.05 \%$ & - & - & GTPase dead & Wehner et al, 2010 \\
\hline & $\Delta 588-591$ & $100 \%$ & + & - & \multirow{2}{*}{$\begin{array}{c}\text { No } \\
\text { isoprenylation }\end{array}$} & \multirow{2}{*}{$\begin{array}{c}\text { Britzen-Laurent et al, } \\
2010\end{array}$} \\
\hline & C588A & $100 \%$ & + & - & & \\
\hline
\end{tabular}

B

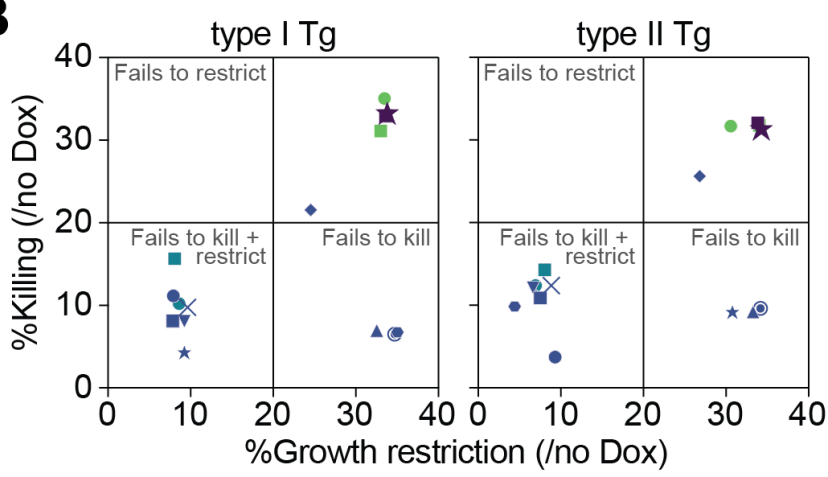

C

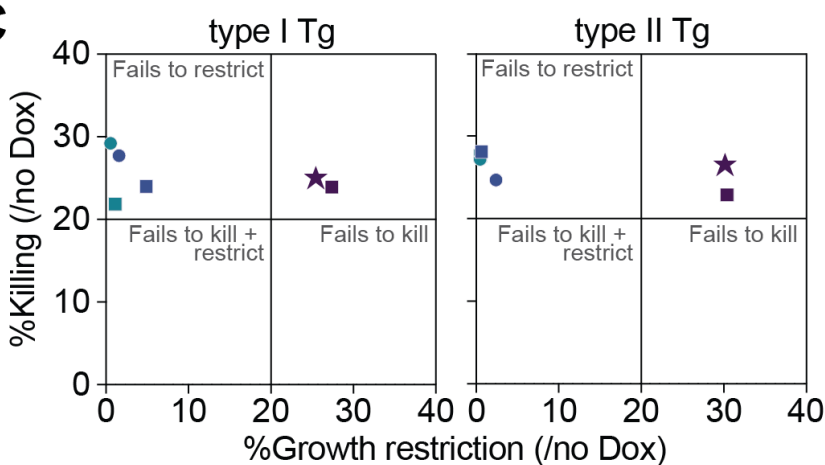

$\triangle{ }^{\triangle G P 2+T e t-G B P 2} 2$ Figure 3: GTPase activity and

D

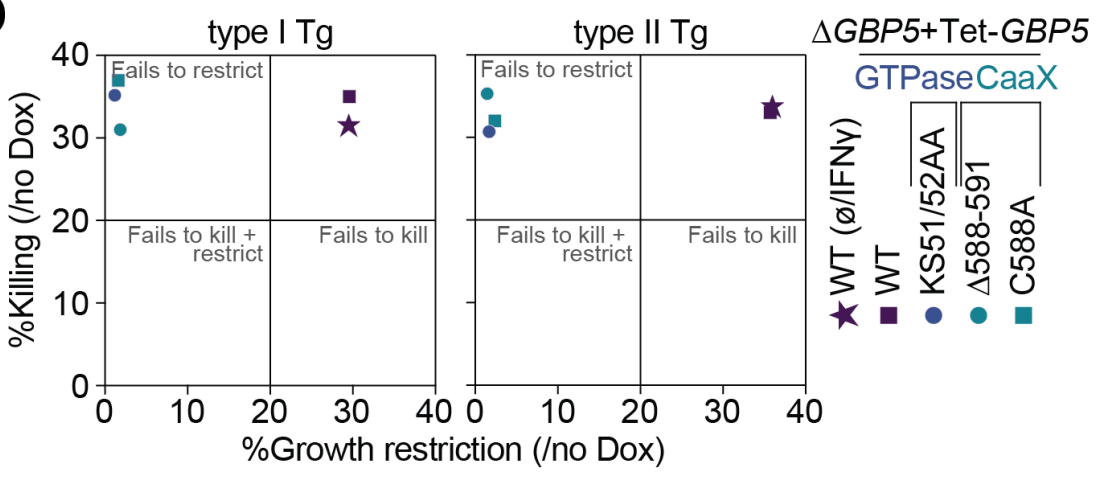

$\triangle G B P 1+$ Tet-GBP1

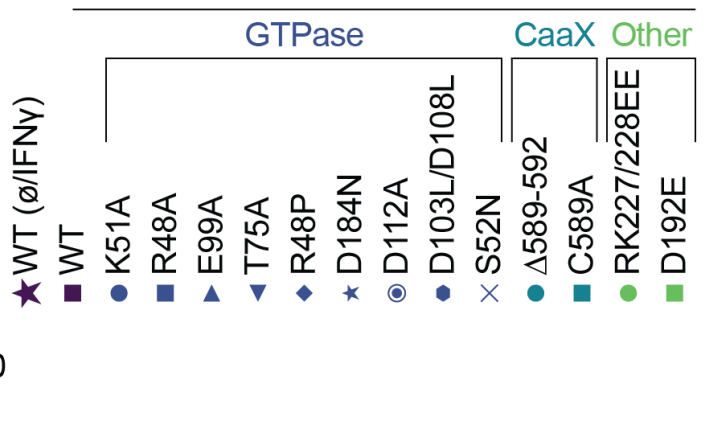

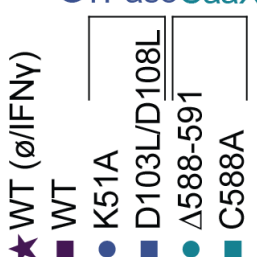
lipidation of GBP1, 2 and 5 are essential for their anti-Toxoplasma activity Overview of GBP1, GBP2 and GBP5 mutants (A). Growth restriction and killing (= ratio between vacuoles and cells) of type I (RH) and type II (PRU) Toxoplasma gondii (Tg) at 18 hours p.i. in THP-1 $\triangle G B P 1+$ Tet-GBP1 cells expressing the indicated mutant of GBP1 (B), $\triangle G B P 2+$ Tet-GBP2 cells expressing the indicated mutant of GBP2 (C), $\triangle G B P 5+$ Tet-GBP5 cells expressing the indicated mutant of GBP5 (D) or of IFNY-treated THP-1 WT cells for each, plotted as proportion between IFNy + Doxycycline (Dox)-treated versus IFNy-only-treated cells. Data information: Graphs in (B-D) show mean from $\mathrm{n}=3$ independent experiments.

Fisch et al. 
GBP2 and 5 do not localize to Toxoplasma vacuoles Comparing findings of the GBP mutant screen indicates a close link between GBP1 GTPase activity/ isoprenylation and the control of $\mathrm{Tg}$ reminiscent of previous results on GBP1 recruitment and correlation to Tg-killing and host cell death (Fisch et al. 2019a, 2020). This suggests a functional link between these processes. Thus, mCherry-tagged GBPx mutants, showing a pathogen growth control phenotype, were created, and transduced into $\triangle G B P x+$ Tet cells to study the localization and spatiotemporal activities (Figure S4). Using $\mathrm{mCH}-\mathrm{GBP} 1 \mathrm{WT}, \mathrm{mCH}-\mathrm{GBP} 2 \mathrm{WT}$ and mCH-GBP5 WT expressing cells, we could confirm that GBP5 was localizing to the Golgi apparatus as had been described before in epithelial cells (Tripal et al. 2007; Britzen-Laurent et al. 2010) (Figure 4A). In IFNy-primed, uninfected cells, GBP1 mutants of the GTPase or isoprenylation site appeared more dispersed in the cytosol instead of showing a granular appearance like GBP1 WT. This might indicate a loss of membrane interactions or aggregate formation (Figure 4B). The GBP1 ${ }^{\text {R584-586A }}$ mutant of the polybasic motif had the most dramatic effect with the protein forming large aggregates within uninfected cells (Figure 4B) as has been observed before (Kohler et al. 2020; Kutsch et al. 2020). The observed dispersed cytoplasmic localization of GBP2 had no obvious differences with mutation of the protein, but GBP5 mutants affecting the GTPase or its isoprenylation had lost their localization at the Golgi (Figure 4B).

In contrast to GBP1, neither GBP2 WT nor GBP5 WT recruited to Tg vacuoles in infected human macrophages implying that they have their growth restrictive function away from the pathogen (pathogendistal) (Figure 4C). We therefore only assessed recruitment of GBP1 mutants to Tg. In agreement with our previous observations of correlation between modulation of macrophage cell death and GBP1 recruitment to pathogens (Fisch et al. 2019a, 2020), all GBP1 GTPase and isoprenylation mutants failed to target $\mathrm{Tg}$ vacuoles in IFNy-primed THP-1 cells (Figure 4D).

In summary, GBP1, GBP2 and GBP5 contributed to the control of $\mathrm{Tg}$ infection via parasite growth restriction and reduction of vacuole/cell numbers in three different human, in vitro macrophage models, including primary-like iPSCs and primary MDMs. Genome engineering and use of a Doxinducible system confirmed GBP1 targeting to pathogen vacuoles to depend on its GTPase activity and isoprenylation. Other infection- and IFNY-treatment-dependent factors are probably involved in regulating its $\mathrm{Tg}$ control function as well. Furthermore, GBP1 needs to be able to produce GMP and be targeted to vacuoles to kill $\mathrm{Tg}$ parasites by reducing vacuole/cell numbers. Surprisingly, GBP2 and GBP5 did not target Tg vacuoles, but were involved in $\mathrm{Tg}$ growth restriction. This function depended on both GBP2 and 5 GTPase activity and isoprenylation.

\section{DISCUSSION}

Here, we employed three in vitro models to study the role of human GBPs in infected macrophages. Gene depletion experiments in THP-1 cells, MDMs and IPSC macrophages established that GBP1, GBP2 and GBP5 control the replication of $\mathrm{Tg}$, while GBP1 was additionally parasiticidal. The findings on pathogen control by GBPs were confirmed using THP-1 CRISPR $\mathrm{KO}$ cell lines and rescued by reconstituting protein expression. Use of an imaging-based assay also allowed to delineate the contribution of individual GBPs to restriction and/or killing, and extend observations made by overall pathogen burden assessment through classical plaque formation assays.

Following IFNY-stimulation, macrophages express GBP1 through 5, but not GBP6 or GBP7, which are predominantly expressed in the oropharyngeal tract (Uhlen et al. 2015) and which was expected since GBP6/7 lack GAS elements in their promoter regions (Tretina et al. 2019). GBP expression patterns resembled expression profiles in mesenchymal stem cells (Qin et al. 2017). Our findings furthermore concur with previous studies showing an effect of human GBP1 on Tg growth in mesenchymal stem cells and in A549 lung epithelial cells (Johnston et al. 2016; Qin et al. 2017). A role for human GBP2 and GBP5 in Tg infection control has so far not been established, but a large body of literature suggests and supports a similar role for their murine homologues (Virreira Winter et al. 2011; Kravets et al. 2012, 2016; Degrandi et al. 2013; Matta et al. 2018).

The three GBP family members that can be isoprenylated (Nantais et al. 1996; Tripal et al. 2007; Britzen-Laurent et al. 2010) contributed to Tg growth restriction, while GBP3 and GBP4 did not. Moreover, these three GBPs were highly upregulated and expressed upon IFNy-stimulation, while GBP3 and GBP4 show significantly lower expression and inducibility in all three human macrophage models studied here. This may indicate a different role for GBP3/4. One conceivable hypothesis is that GBP3/4 regulate lipidated GBPs through heterotypic interactions, partially resembling the Irg system of the mouse, in which GMS-Irgs control the activity of the GKS-Irgs (Hunn et al. 2008; Haldar et al. 2013, 2016).

It is likely that GBP1, 2 and 5 act in concert. siRNA-depletion and Dox-reconstitution experiments suggest that for growth restriction all three GBPs are needed, since depletion of a single member abolished restriction and conversely reconstitution of a single member did not rescue the loss of restriction in the CRISPR KO cells. Growth restriction alone was not able to reduce the overall parasite burden. For this to occur, Tg-killing mediated by GBP1 was required. Similar hierarchical organization of the human GBP system was observed during Shigella flexneri infection where the pathfinder GBP1 first targets the pathogen thus facilitating recruitment of GBP2/3 and GBP4 (Piro et al. 2017; Wandel et al. 2017). It is likely that similar 
cooperation is needed between GBP1, 2 and GBP5 for their pathogen-distal action against Tg. Additionally, it is probable that GBP1 also has a pathogen-distal function for $\mathrm{Tg}$ growth restriction, as mutants that cannot produce GMP do not localize to the PV but still restrict the parasite growth. These GBP1 mutants therefore resemble the function of GBP2/5.

In uninfected cells GBP1, GBP2 and GBP5 showed differing localizations: GBP1 had a granular appearance suggesting aggregate formation or (endo-)membrane interaction, GBP2 was uniformly distributed in the cytosol and GBP5 associated with the Golgi apparatus, resembling prior observations in HeLa cells (Britzen-Laurent et al. 2010). It is known that correct localization of the three isoprenylated GBPs depends on lipidation with farnesyl (GBP1) or geranylgeranyl (GBP2/5) (Britzen-Laurent et al. 2010). Accordingly, mutation of the CaaX box of either of the three GBPs led to uniform cytoplasmic distribution. Since GBP $1 / 2 / 5$ all show differing subcellular localizations despite all being isoprenylated, other parts of the proteins must contribute to their correct trafficking. One example could be the polybasic motif of GBP1 (R584-586), which when mutated led to the pronounced phenotype of protein aggregation, as observed by other groups too (Kohler et al. 2020; Kutsch et al. 2020).

GBP1, 2 and 5 have all been localized at the Golgi in previous studies (Modiano, Lu and Cresswell 2005; Tripal et al. 2007; Britzen-Laurent et al. 2010; Krapp et al. 2016; Braun et al. 2019). Aluminium fluoride treated HeLa cells or HFFs showed accumulation of GBP1 at the Golgi, suggesting that this only occurs in a GTP-locked conformation (Modiano, Lu and Cresswell 2005). GBP5 has a well-established localization at the Golgi and can further recruit GBP2 (Britzen-Laurent et al. 2010; Braun et al. 2019). In line with our results, isoprenylation of GBP5 was required for this. Localization of GBP5 at the Golgi is needed for its antiviral activity against HIV (Krapp et al. 2016), which is achieved by concerted action of GBP2 and GBP5, together reducing the activity of Furin protease (Braun et al. 2019). Since GBP5 GTPase and isoprenylation mutants lost their association with the Golgi apparatus, it is likely that GBP5 activity against $\mathrm{Tg}$ relies on its correct localization to the Golgi. Thus, GBP1/2/5 influence $\mathrm{Tg}$ growth by acting without accumulation of the proteins at the pathogen (pathogen-distal), which has been observed before for GBP1 in A549 lung-epithelial cells (Johnston et al. 2016) but contests the dogma of defense protein accumulation at the intracellular infection site (MacMicking 2012). It is tempting to speculate that the GBPs therefore have additional functions during infection other than recruiting to pathogens.

Apart from Tg-restriction mechanism(s), GBP1 accumulated at $\mathrm{Tg}$ vacuoles in infected cells. Neither GBP2 nor GBP5 recruited to Tg. The recruitment of GBP1 was dependent on its GTPase function and isoprenylation. GBP1 recruitment might also rely on other proteins, as its association with $\mathrm{Tg}$ appears celltype- and IFNy-dependent. It will therefore be interesting to study GBP1-interactomes. Comparative study of macrophage and A549 lung epithelial cell GBP1-interactomes might offer the opportunity to identify critical GBP1 trafficking factors. Overall, recruitment of GBP1 to Tg resembles the function of its murine homologue, which is known to associate with bacterial pathogens (Kim et al. 2011; Haldar et al. 2014; Meunier et al. 2014, 2015; Finethy et al. 2015; Man et al. 2015; Feeley et al. 2017; Wallet et al. 2017; Zwack et al. 2017; Lindenberg et al. 2017; Balakrishnan et al. 2018; Liu et al. 2018) and Tg-PVs and was also found directly on the parasites (Virreira Winter et al. 2011; Kravets et al. 2012, 2016; Degrandi et al. 2013; Haldar et al. 2014, 2015; Costa Franco et al. 2018).

Careful examination of the effect of different mutations of the GBP1 GTPase activity (Praefcke et al. 2004; Modiano, Lu and Cresswell 2005; Abdullah, Balakumari and Sau 2010) revealed that full GTPase activity was needed for recruitment to $\mathrm{Tg}$ and killing of the pathogen, while GMP formation was dispensable for growth restriction. Interestingly, GBP1 was the only parasiticidal GBP family member, a function which may therefore rely on the formation of GMP. Similar observations have been made for Chlamydia infections, where GMP formation was necessary for pathogen and host-cell killing, but dispensable for Chlamydia growth restriction (Xavier et al. 2020). Conversely, GBP5 which cannot produce GMP by hydrolysis of GDP (Wehner and Herrmann 2010), did not kill Tg. GBP2 however, which like GBP1, can hydrolyze GDP to GMP (Abdullah, Balakumari and Sau 2010), did not kill Tg. GTPase activity of GBP2 and GBP5 were nevertheless needed for Tg-growth restriction.

Taken together these results show that killing of Tg relies on GBP1 recruitment to the pathogens and a pathogen-proximal function involving the formation of GMP, whereas GBP1, 2 and 5 restrict Tg-growth via a thus far unknown pathogen-distal function. 


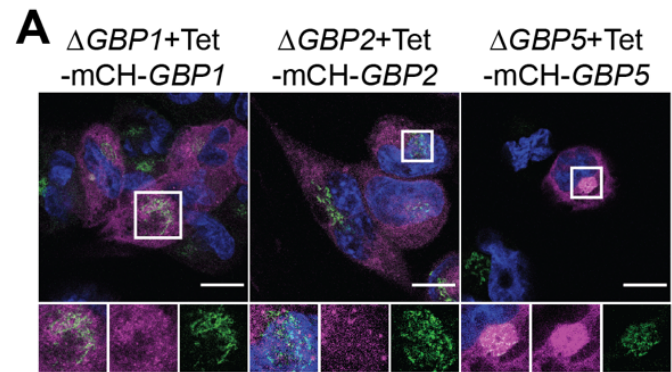

mCH-GBPx, GM-130 (Golgi), Nuclei
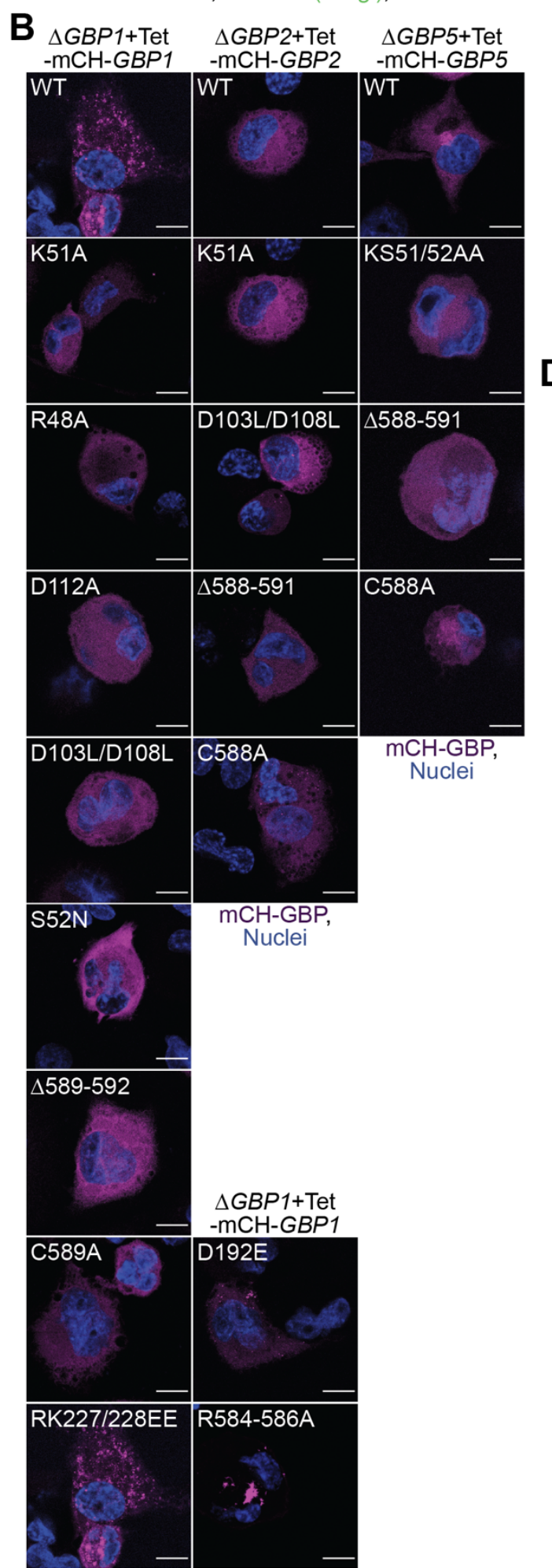

mCH-GBP, Nuclei
C
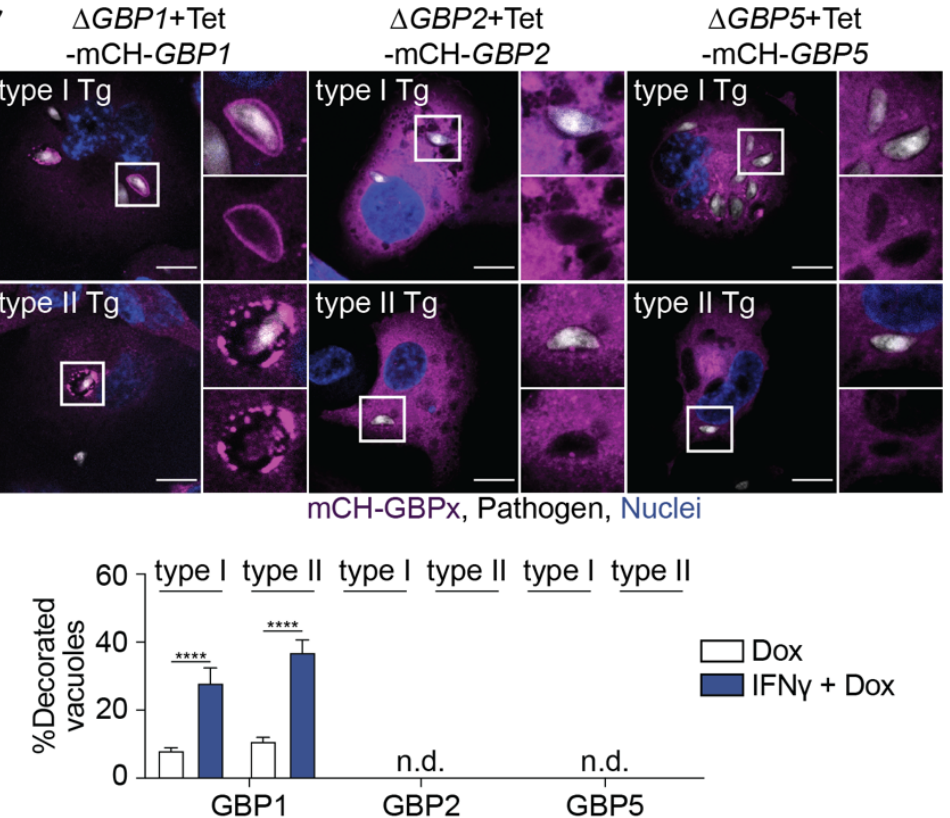

D THP-1 $\triangle G B P 1+$ Tet-mCH-GBP1+IFNy +Dox

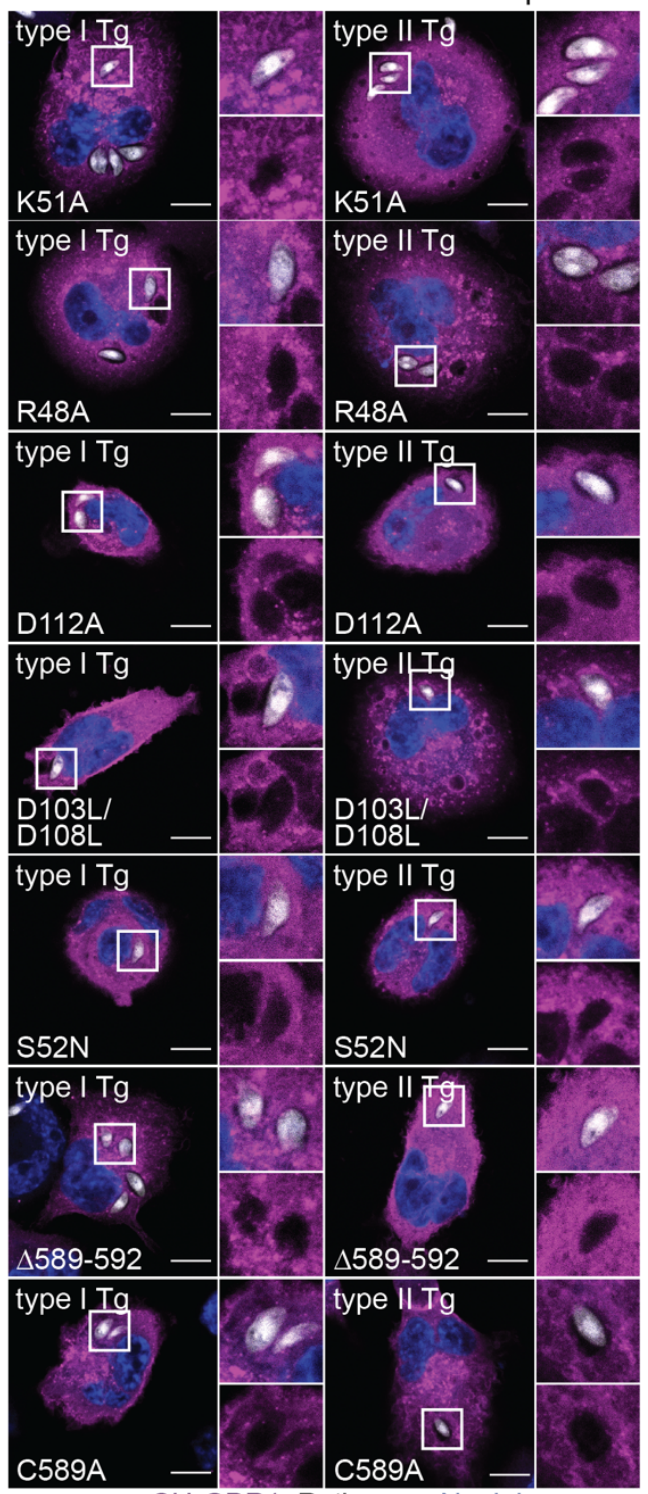

$\triangle G B P 1+$ Tet-mCH-GBP1
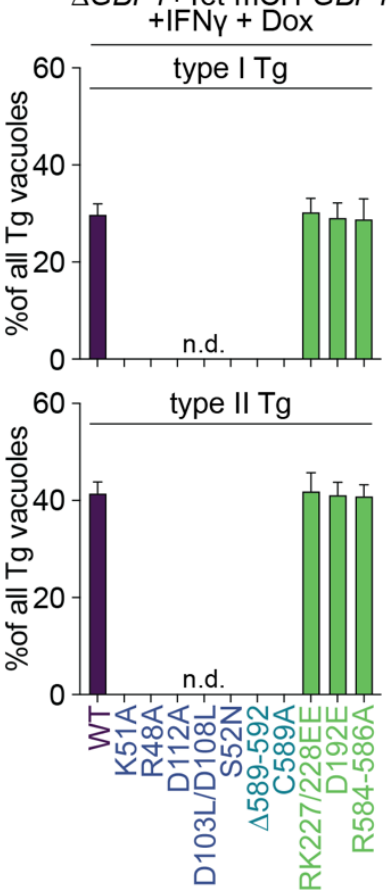

GBP1 mutation

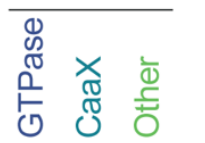


Figure 4: GBP2 and 5 do not localize to Toxoplasma vacuoles

(A) Immunofluorescence images of THP-1 $\triangle G B P 1+T e t-m C H-G B P 1, \triangle G B P 2+T e t-m C H-G B P 2$ or $\triangle G B P 5+T e t-m C H-G B P 5$ cells treated with IFNY and Doxycycline (Dox) and stained for Golgi marker GM-130 to illustrate Golgi localization of GBP5 in uninfected cells. Magenta: mCherry (mCH)-GBP1/2/5; Green: GM-130 (Golgi); Blue: nuclei. Scale bar, $10 \mu \mathrm{m}$. (B) Immunofluorescence images of THP-1 $\triangle G B P 1+T$ et-mCH-GBP1, $\triangle G B P 2+$ Tet-mCH-GBP2 or $\triangle G B P 5+$ Tet-mCH-GBP5 cells expressing the indicated GBPx mutant treated with IFNY+Dox to illustrate localization of the respective protein in uninfected cells. Magenta: mCherry (mCH)-GBP1; Blue: nuclei. Scale bar, $10 \mu \mathrm{m}$. (C) Immunofluorescence images (top) and HRMAn-based quantification of GBP recruitment to $\mathrm{Tg}$ (bottom) in THP-1 $\triangle G B P 1+T e t-m C H-G B P 1, \triangle G B P 2+T e t-m C H-G B P 2$ or $\triangle G B P 5+$ Tet-mCH-GBP5 cells treated with IFNY+Dox and infected with type I $(\mathrm{RH})$ or type II (PRU) Toxoplasma gondii (Tg) for 6 hours. Magenta: mCherry (mCH)-GBP1/2/5; Grey: Tg; Blue: nuclei. Scale bar, $10 \mu \mathrm{m}$. (D) Images (left) and HRMAn-based quantification of GBP1 recruitment to Tg-vacuoles (right) in THP-1 $\triangle G B P 1+T e t-m C H-G B P 1$ cells expressing the indicated GBP1 mutant treated with IFNy+Dox and infected for 6 hours. Magenta: mCherry (mCH)-GBP1; Grey: pathogen; Blue: nuclei. Scale bar, $10 \mu \mathrm{m}$. Data information: Images in (A+C-D) representative of $n=3$ and in (B) representative of $n=2$ independent experiments. Graph in (C+D) show mean \pm SEM from $n=3$ independent experiments. ${ }^{* * *} P \leq 0.0001$ for indicated comparisons in (C) from one-way ANOVA comparing to Dox-only treated cells following adjustment for multiple comparisons; n.d. not detected.

\section{AUTHOR CONTRIBUTION}

DF and EMF conceived the project. DF conducted the experiments. BC set up and assisted with imaging experiments. RK and LH set up initial iPS cell culture. DF and EMF wrote the manuscript. EMF supervised the project. EMF acquired funding related to the project.

\section{CONFLICT OF INTEREST}

The authors declare no conflict of interest.

\section{ACKNOWLEDGEMTS}

The authors would like to acknowledge all members of the Frickel lab (University of Birmingham, UK) for critical discussion of this study and Mike Howell from the HTS STP at the Francis Crick Institute for his help with high-throughput image acquisition.

\section{FUNDING}

This research was funded, in whole or in part, by The Wellcome Trust. A CC BY license is applied to the AAM arising from this submission, in accordance with the grant's open access conditions. EMF is supported by a Wellcome Trust Senior Research Fellowship (217202/Z/19/Z). This work was supported by the Francis Crick Institute, which receives its core funding from Cancer Research UK (FC001076 to EMF, FC001999 to LH), the UK Medical Research Council (FC001076 to EMF, FC001999 to LH), and the Wellcome Trust (FC001076 to EMF, FC001999 to LH). DF was supported by a Boehringer Ingelheim Fonds PhD fellowship.

\section{MATERIALS AND METHODS}

Cell and parasite culture, treatments, and infection THP-1 (TIB202, ATCC) were maintained in RPMI with GlutaMAX (35050061, Gibco) and 10\% FBS (Sigma), HFFs (SCRC 1041, ATCC) and HEK293T (Cell Services, The Francis Crick Institute, London, UK) were maintained in DMEM with GlutaMAX and $10 \%$ FBS at $37^{\circ} \mathrm{C}$ in $5 \% \mathrm{CO}_{2}$. THP-1s were differentiated with $50 \mathrm{ng} \mathrm{mL}^{-1}$ phorbol 12-myristate 13-acetate (PMA, $P 1585$, Sigma) for 3 days and then rested for 2 days in PMA-free, complete medium. All cells were regularly tested for mycoplasma by immunofluorescence and PCR. Cells were stimulated for $16 \mathrm{~h}$ prior to infection with addition of $50 \mathrm{IU} \mathrm{mL} \mathrm{L}^{-1}$ human IFNY (285-IF, R\&D Systems). Induction of GBP expression in the Dox-inducible cells was performed with $200 \mathrm{ng} \mathrm{mL}^{-1}$ Dox overnight (D9891, Sigma).

Tg were maintained by serial passage on HFF cell monolayers and passaged onto new HFFs the day before infection. $\mathrm{Tg}$ were prepared from freshly $25 \mathrm{G}$ syringe lysed cultures by centrifugation at $50 \times \mathrm{g}$ for 3 minutes, transferring the cleared supernatant into a new tube, subsequent centrifugation at $500 \mathrm{x} g$ for 7 minutes and re-suspension of the pelleted parasites into fresh complete medium. Parasite-suspension was added to the cells at a MOI of 1 . The cell cultures with added $\mathrm{Tg}$ were then centrifuged at $500 \mathrm{xg}$ for 5 minutes to synchronize infection. Two hours post-infection, extracellular parasites were removed with three PBS washes (806552, Sigma) and fresh complete medium added prior to culturing at $37^{\circ} \mathrm{C}, 5 \% \mathrm{CO}_{2}$ for the required time.

\section{iPS cell culture and monocyte/macrophage production}

Production of monocytes from KOLF iPSC (HESCU STP, The Francis Crick Institute, London, UK) was previously described (Wilgenburg et al. 2013). KOLF cells were maintained in their pluripotent state in a feeder-free, serum-free culture system at $37^{\circ} \mathrm{C}$ in $5 \% \mathrm{CO}_{2}$ using Synthemax ${ }^{\mathrm{TM}}$ II-SC Substrate-coated plates (3535, Corning) and mTeSRTM-1 medium (85850, StemCell Technologies). Cells were clump-passaged when colonies covered $\sim 75 \%$ of the wells by washing with PBS, detaching using Collagenase IV (07427, StemCell Technologies), followed by gentle scraping in mTeSRTM-1 medium. Cells were split roughly 1:4 and supplemented with 1 mM Rock-inhibitor (Y27632; Calbiochem). Cells were fed with new media daily.

To create monocyte production factories KOLF cells were washed with PBS and harvested with TrypLE Express (12604021, Gibco), dissociated into single cells by pipetting and finally diluted 1:10 with PBS and collected in a centrifuge tube. Cells were pelleted by centrifugation and resuspended in mTeSRTM-1 supplemented with $1 \mathrm{mM}$ Rock-inhibitor, $50 \mathrm{ng} \mathrm{mL}^{-1}$ BMP-4 (120-05, Peprotech), 20 ng mL $^{-1}$ SCF (130-093991, Miltenyi), $50 \mathrm{ng} \mathrm{mL}^{-1}$ VEGF (100-20, Peprotech) 
(= EB medium). Next, AggreWell ${ }^{\mathrm{TM}} 800$ plates (34811, StemCell Technologies) were prepared by rinsing with PBS, addition of $1 \mathrm{~mL}$ EB medium to each well and centrifugation at $3,000 \times \mathrm{g}$ for 2 minutes. Then $1 \mathrm{~mL}$ of harvested cells were added per well, the plate centrifuged at $150 \times \mathrm{g}$ for 3 minutes and left in the incubator for four days. EBs were fed daily with fresh EB medium by stepwise exchanging $75 \%$ of medium. EBs were harvested by dislodging through pipetting, transferring the well-contents onto a $40 \mathrm{~mm}$ strainer, rinsing with PBS and collecting them into a new tube. 500 EBs were transferred per T175 tissue culture flasks in $20 \mathrm{~mL}$ X-VIVO ${ }^{\text {TM }} 15$ (04-418Q, Lonza), supplemented with $100 \mathrm{ng} \mathrm{mL}^{-1} \mathrm{M}-\mathrm{CSF}$ (PHC9504, Gibco), $25 \mathrm{ng} \mathrm{mL}^{-1}$ IL-3 (203-GMP, R\&D Systems), 2 mM GlutaMAX, $100 \mathrm{U} \mathrm{mL}^{-1}$ penicillin/streptomycin (15140122, Invitrogen), and $0.05 \mathrm{mM} \quad \beta$-Mercaptoethanol (21985023, Gibco). Roughly 2-3 weeks following seeding, monocytes in suspension appeared and were harvested fortnightly from the supernatant. Monocytes were differentiated into macrophages in X-VIVO ${ }^{\mathrm{TM}} 15$ supplemented with $100 \mathrm{ng} \mathrm{mL}^{-1} \mathrm{M}-\mathrm{CSF}$ for 5 days.

\section{Primary human macrophage isolation and culture} PBMCs were extracted from Leukocyte cones from healthy donors (NHS) via Ficoll (17544202, GE Healthcare) density gradient centrifugation. CD14 ${ }^{+}$ monocytes were extracted using magnetic microbeads (130-050-201, MACS Miltenyi). Monocytes were counted, seeded, and differentiated for one week in RPMI containing $10 \%$ human $A B$ serum $(\mathrm{H} 4522$, Sigma), GlutaMAX, penicillin/streptomycin and $5 \mathrm{ng} \mathrm{mL}^{-1}$ hGM-CSF (130-093-864, Miltenyi). The medium was replaced after 2 and 5 days, to replenish the hGM-CSF.

\section{SiRNA transfection}

Cells were transfected two days prior to infection, at the time the THP-1 differentiation medium was replaced, or MDM/iPSC differentiation medium was replaced on day 5 after seeding. All siRNAs were used at a final concentration of $30 \mathrm{nM}$. To set up the transfection mix, a 10x mix was prepared in OptiMEM containing the appropriate siRNA(s) and TransIT-X2 transfection reagent (MIR 600x, Mirus) in a 1:2 stoichiometry. As the GBPs exhibit high sequence similarity, a costume transfection panel using three different Silencer ${ }^{\mathrm{TM}}$ Select siRNAs (Ambion: GBP1: s5620, s5621, s5622; GBP2: s5623, s5624, s5625; GBP3: s5626, s5627, s5628; GBP4: s41805, s41806, s41807; GBP5: s41808, s41809, s41810) was used (Fisch et al. 2019a). The appropriate negative control was Silencer ${ }^{\mathrm{TM}}$ Select Negative Control No. 1 siRNA (\#4390843, Ambion).

\section{Plaque assays}

$0.8 \times 10^{6}$ differentiated THP- 1 cells were infected with $\mathrm{Tg}$ as described above and 18 hours p.i. supernatant and cells were harvested from the wells of a 12-well plate. Cells were syringe-lysed and obtained parasites from within the cells and the supernatant diluted $1: 10,000$ and added to HFFs grown confluent in wells of a 24-well plate.

Determination of plaque sizes and number was performed 5 days p.i. of the HFFs, when cells were fixed with ice-cold methanol and stained with crystal violet (C6158, Sigma). Following 5 washes with PBS, plaques were imaged on a GelCount ${ }^{\mathrm{TM}}$ Colony Counter (Oxford Optronix) and cell covered area determined using FIJI. Proportions of plaque and plaque loss, as compared to $\mathrm{Tg}$ grown in untreated THP-1, were calculated.

\section{Flow cytometry}

$1 \times 10^{6}$ differentiated macrophages were harvested using accutase (A6964, Sigma) and scraping and washed twice with warm PBS. Cells were resuspended in PBS $+1 \%$ BSA containing dilutions of fluorescently labelled antibodies against surface receptors and incubated for 1 hour at room temperature in the dark. Cells were washed with PBS, fixed with $4 \%$ formaldehyde for 15 minutes at room temperature and washed again, prior to resuspension in PBS $+1 \%$ BSA. All samples were analyzed on a LSR Fortessa (BD Biosciences), and recorded data was processed using FlowJo 10.3 (FlowJo, LLC).

\section{RT-qPCR}

RNA was extracted from $0.25 \times 10^{6}$ cells using Trizol reagent (15596026, Invitrogen). $5 \mu \mathrm{g} \mathrm{mL}^{-1}$ GlycoBlue (AM9516, Invitrogen) was added during the isopropanol (190764, Sigma) precipitation to increase RNA-yields. RNA quality was measured on a Nanodrop

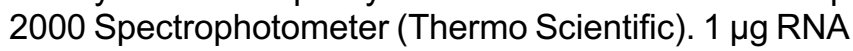
was reverse transcribed using high-capacity CDNA synthesis kit (4368813, Applied Biosystems). qPCR used PowerUP SYBR green (A25742, Applied Biosystems), $20 \mathrm{ng} \mathrm{cDNA}$ in a $20 \mu \mathrm{L}$ reaction and primers at $1 \mu \mathrm{M}$ final concentration on a QuantStudio 12K Flex Real-Time PCR System (Applied Biosystems). Primer specificity was ensured by designing primers to span exon-exon junctions, whenever possible, and for each primer pair a melt curve was recorded (see Table 2). Ct values were normalized to the $\mathrm{Ct}$ of human HPRT1. To determine absolute expression of GBPs, a defined amount of linearised plasmid standards was added as PCR template and obtained $\mathrm{Ct}$ values used to calculate transcript numbers from the samples.

\section{Creation of new cell lines}

THP-1 $1 \triangle G B P 1$ and the Dox-inducible system were previously published (Fisch et al. 2019a). THP-1 $1 \triangle G B P 5$ were a gift from Frank Kirchhoff (Krapp et al. 2016). Guide RNA (gRNA) sequences targeting the 5' and 3' UTR of GBP2 gene were designed using cripr.mit.edu. DNA oligonucleotides encoding for the crRNAs (sgRNA1: 5'-CACCGTGTCTTACAAATTGGG TCAC-3'; sgRNA2: 5'-CACCGCATGAGTTGAATTGC TCTGT-3') were annealed by mixing in equimolar ratios 
and boiling at $95^{\circ} \mathrm{C}$ for 15 minutes followed by a slow decrease to room temperature. Annealed oligos were then cloned into BsmBI-digested (ER0451, Thermo Scientific) pLentiCRISPR-V2 backbone (Sanjana, Shalem and Zhang 2014) using Quick Ligation ${ }^{\top M}$ kit (M2200, NEB) and transduced into THP-1 WT cells using Lentiviral particles (Fisch et al. 2019a). Following selection with $1 \mathrm{\mu g} \mathrm{mL}^{-1}$ Puromycin (A1113802, Gibco) for 14 days, cells were sub-cloned by serial dilution into ten 96-well plates using pre-conditioned complete medium supplemented with non-essential amino acids (11140076, Gibco), penicillin/streptomycin and GlutaMAX. Roughly 3 weeks after seeding of the single cells, obtained clones were expanded into 24-well plates with $2 \mathrm{~mL}$ fresh medium and screened for absence of $G B P 2$ expression by RT-qPCR. Clones that showed reduced or absent GBP2 expression underwent secondary screening by immunoblotting. Finally, confirmed $\mathrm{KO}$ clones were tested again by Sanger sequencing of the genomic target locus, RTqPCR, and immunoblotting.

Cells with Dox-inducible expression were created as previously published (Fisch et al. 2019a). To create plasmids that express GBP1, GBP2 or GBP5 under the control of Dox, RNA from IFNy-treated THP-1s was extracted and cDNA synthesized as described above. The CDS of GBP mRNA was amplified with Q5 polymerase, the amplicons treated with Taq polymerase (M0273, NEB) to create Aoverhangs and cloned into pCR2.1 ${ }^{\circledR}$-TOPO TA vector using TOPO TA kit (451641, Invitrogen). GBP mutants were created by site-directed mutagenesis, introducing single point mutations with mismatch-primers and PCR with Q5 polymerase. Using the mutated or wildtype GBP-containing vectors, the ORFs were PCR-amplified to create overhangs to pLenti-Tet vector. Gibson assemblies of the digested backbone and the GBP ORFs were performed, and successful cloning confirmed by Sanger sequencing. To create $\mathrm{mCH}$-tagged versions, $\mathrm{mCH}-\mathrm{ORF}$ was amplified with overlaps to the backbone and the GBP ORF and included in the Gibson assembly reactions. GBP ORFs lacking the C-terminal CaaX-box were amplified with primers excluding parts of the wildtype GBP ORFs.

\section{SDS-PAGE and immunoblotting}

$0.5 \times 10^{6}$ cells were seeded per well of a 48 -well plate, differentiated, and treated as described above. At the end of treatments, cells were washed with ice-cold PBS and lysed for $5 \mathrm{~min}$ on ice in $50 \mu \mathrm{L}$ RIPA buffer $(150 \mathrm{mM}$ $\mathrm{NaCl}, 1 \%$ Nonidet P-40, $0.5 \%$ Sodium deoxycholate, $0.1 \%$ SDS, $25 \mathrm{mM}$ Tris-HCl pH 7.4) supplemented with protease inhibitors (Protease Inhibitor Cocktail set III, EDTA free, Merck) and PhosSTOP phosphatase inhibitors (4906845001, Roche). Lysates were cleared by centrifugation at full speed for 15 minutes at $4^{\circ} \mathrm{C}$. BCA assay (Pierce BCA protein assay kit, 23225, Thermo Scientific) was performed to determine protein concentrations. $10 \mu \mathrm{g}$ of total protein per sample were mixed with Laemmli buffer (\#1610737, Biorad) containing 5\% DTT (646563-10X, Sigma) and boiled at $95^{\circ} \mathrm{C}$ for 10 minutes and then run on Bis-Tris gels (Novex, Invitrogen) in MOPS running buffer.

Following SDS-PAGE, proteins were transferred onto Nitrocellulose membranes using iBlot transfer system (Invitrogen). Membranes were blocked with either 5\% BSA (A2058, Sigma) or 5\% dry-milk (M7409, Sigma) in TBS-T $(0.05 \%$ Tween-20) for at least $1 \mathrm{~h}$ at room temperature. Incubation with primary Abs (see Table 3) was performed at $4^{\circ} \mathrm{C}$ overnight. Blots were developed by washing the membranes with TBS-T, probed with 1:5,000 diluted HRP-conjugated secondary Abs in 5\% BSA in TBS-T and washed again. Finally, the membranes were incubated for 2 minutes with ECL (Immobilon Western, WBKLS0500, Millipore) and chemiluminescence recorded on a ChemiDoc MP imaging system (Biorad).

\section{Microscopy}

$0.25 \times 10^{6}$ cells were seeded on gelatin-coated (G1890, Sigma) coverslips in 24-well plates. Following differentiation, treatments and infection, cells were washed three times with warm PBS, prior to fixation, to remove any uninvaded pathogens and then fixed with 4\% methanol-free formaldehyde (28906, Thermo Scientific) for $15 \mathrm{~min}$ at room temperature. For high-throughput imaging 50,000 cells were seeded of a black-wall, clear bottom 96-well imaging plate (Thermo Scientific), differentiated, and treated and fixed as described above.

Following fixation, cells were washed again with PBS and kept at $4^{\circ} \mathrm{C}$ overnight to quench any unreacted formaldehyde. Fixed specimens were permeabilized with PermQuench buffer $(0.2 \%(\mathrm{w} / \mathrm{v})$ BSA and $0.02 \%(w / v)$ saponin in PBS) for 30 minutes at room temperature and then stained with primary Abs (see Table 3) for one hour at room temperature. After three washes with PBS, cells were incubated with the appropriated fluorescently labelled secondary $A b$ and $1 \mu \mathrm{g} \mathrm{mL}^{-1}$ Hoechst 33342 (H3570, Invitrogen) diluted in PermQuench buffer for 1 hour at room temperature. Cells were washed with PBS five times and mounted using $5 \mu \mathrm{L}$ Mowiol. For high-throughput imaging, fixed and permeabilized specimens were stained for 1 hour at room temperature by adding PermQuench buffer containing $1 \mu \mathrm{g} / \mathrm{mL}$ Hoechst 33342 and $2 \mu \mathrm{g} \mathrm{mL}-1$ CellMask $^{\mathrm{TM}}$ Deep Red plasma membrane stain (H32721, Invitrogen). After staining, the specimens were washed with PBS five times and kept in $200 \mu \mathrm{L}$ PBS per well for imaging.

Coverslips were imaged on a Leica SP5inverted confocal microscope using 100x magnification and analyzed using LAS-AF software. Plates were imaged on a Cell Insight CX7 High-Content Screening (HCS) Platform (Thermo Scientific) using 20x magnification. Following acquisition, images were exported from HCS Studio Cell Analysis as single channel 16-bit .tiff files before they were fed into the HRMAn analysis pipeline (Fisch et al. 2019b, 2021). 


\section{Data handling and statistics}

Data was plotted using Prism 8.4.0 (GraphPad Inc.) and presented as means of $n=3$ experiments (with usually 3 technical repeats within each experiment) with error bars as standard error of the mean (SEM), unless stated otherwise. Significance of results was determined by non-parametric one-way ANOVA or twoway ANOVA as indicated in the figure legends. Benjamini, Krieger and Yekutieli false-discovery rate $(Q$ $=5 \%$ ) based correction for multiple comparisons as implemented in Prism was used when making more than 3 comparisons.

\section{REFERENCES}

Abdullah N, Balakumari M, Sau AK. Dimerization and its role in GMP formation by human guanylate binding proteins. Biophys $J$ 2010;99:2235-44.

Balakrishnan A, Karki R, Berwin B et al. Guanylate binding proteins facilitate caspase-11-dependent pyroptosis in response to type 3 secretion system-negative Pseudomonas aeruginosa. Cell Death Discov 2018;4:66.

Barz B, Loschwitz J, Strodel B. Large-scale, dynamin-like motions of the human guanylate binding protein 1 revealed by multi-resolution simulations. Kasson PM (ed.). PLoS Comput Biol 2019;15:e1007193. Boehm U, Guethlein L, Klamp T et al. Two families of GTPases dominate the complex cellular response to IFN-gamma. J Immunol 1998;161:6715-23.

Braun E, Hotter D, Koepke L et al. Guanylate-Binding Proteins 2 and 5 Exert Broad Antiviral Activity by Inhibiting Furin-Mediated Processing of Viral Envelope Proteins. Cell Rep 2019;27:20922104.e10.

Britzen-Laurent N, Bauer M, Berton V et al. Intracellular trafficking of guanylate-binding proteins is regulated by heterodimerization in a hierarchical manner. PLoS One 2010;5:e14246.

Chanput W, Mes JJ, Wichers HJ. THP-1 cell line: An in vitro cell model for immune modulation approach. Int Immunopharmacol 2014;23:37-45.

Cheng YSE, Becker-Manley MF, Chow TP et al. Affinity purification of an interferon-induced human guanylate-binding protein and its characterization. J Biol Chem 1985;260:15834-9.

Clough B, Frickel E-M. The Toxoplasma Parasitophorous Vacuole: An Evolving Host-Parasite Frontier. Trends Parasitol 2017;33:47388 .

Costa Franco MM, Marim F, Guimarães ES et al. Brucella abortus Triggers a cGAS-Independent STING Pathway To Induce Host Protection That Involves Guanylate-Binding Proteins and Inflammasome Activation. J Immunol 2018;200:607-22.

Cronkite DA, Strutt TM. The regulation of inflammation by innate and adaptive lymphocytes. J Immunol Res 2018;2018:e1467538.

Daffos F, Forestier F, Capella-Pavlovsky $M$ et al. Prenatal Management of 746 Pregnancies at Risk for Congenita Toxoplasmosis. N Engl J Med 1988;318:271-5.

Darnell JE, Kerr IM, Stark GR. Jak-STAT pathways and transcriptional activation in response to IFNs and other extracellular signaling proteins. Science 1994;264:1415-21.

Degrandi D, Kravets E, Konermann C et al. Murine Guanylate Binding Protein 2 (mGBP2) controls Toxoplasma gondii replication. Proc Natl Acad Sci USA 2013;110:294-9.

Desmonts G, Forestier F, Thulliez $\mathrm{P}$ et al. Prenatal Diagnosis of congenital Toxoplasmosis. Lancet 1985;325:500-4.

Dinarello CA. Historical insights into cytokines. Eur J Immunol 2007;37:S34-45.

Feeley EM, Pilla-Moffett DM, Zwack EE et al. Galectin-3 directs antimicrobial guanylate binding proteins to vacuoles furnished with bacterial secretion systems. Proc Natl Acad Sci USA 2017;114:E1698-706.

Feghali CA, Wright TM. Cytokines in acute and chronic inflammation. Front Biosci 1997;2, DOI: 10.2741/a171.

Finethy R, Jorgensen I, Haldar AK et al. Guanylate binding proteins enable rapid activation of canonical and noncanonical inflammasomes in Chlamydia-infected macrophages. Infect Immun 2015;83:4740-9.

Fisch D, Bando $\mathrm{H}$, Clough $\mathrm{B}$ et al. Human GBP1 is a microbe-specific gatekeeper of macrophage apoptosis and pyroptosis. EMBO J 2019a;38:e100926.

Fisch D, Clough B, Domart M-C et al. Human GBP1 Differentially Targets Salmonella and Toxoplasma to License Recognition of Microbial Ligands and Caspase-Mediated Death. Cell Rep 2020;32:1-14.

Fisch D, Evans R, Clough B et al. HRMAn 2.0: Next-generation artificial intelligence-driven analysis for broad host-pathogen interactions. Cell Microbiol 2021;23:e13349.

Fisch D, Yakimovich A, Clough B et al. Defining host-pathogen interactions employing an artificial intelligence workflow. Elife 2019b;8:e40560.

Gazzinelli RT, Hieny S, Wynn TA et al. Interleukin 12 is required for the T-lymphocyte-independent induction of interferon $Y$ by an intracellular parasite and induces resistance in T-cell- deficient hosts. Proc Natl Acad Sci USA 1993;90:6115-9.

Gazzinelli RT, Wysocka M, Hayashi S et al. Parasite-induced IL-12 stimulates early IFN-gamma synthesis and resistance during acute infection with Toxoplasma gondii. J Immunol 1994;153:2533-43.

Ghosh A, Praefcke GJKK, Renault L et al. How guanylate-binding proteins achieve assembly-stimulated processive cleavage of GTP to GMP. Nature 2006;440:101-4.

Green DR, Oguin TH, Martinez J. The clearance of dying cells: Table for two. Cell Death Differ 2016;23:915-26.

Haldar AK, Foltz C, Finethy $\mathrm{R}$ et al. Ubiquitin systems mark pathogencontaining vacuoles as targets for host defense by guanylate binding proteins. Proc Natl Acad Sci USA 2015;112:E5628-37.

Haldar AK, Piro AS, Finethy $R$ et al. Chlamydia trachomatis is resistant to inclusion ubiquitination and associated host defense in gamma interferon-primed human epithelial cells. MBio 2016;7:e01417-16

Haldar AK, Piro AS, Pilla DM et al. The E2-like conjugation enzyme Atg3 promotes binding of IRG and Gbp proteins to Chlamydia- and Toxoplasma-containing vacuoles and host resistance. PLoS One 2014;9:e86684.

Haldar AK, Saka HA, Piro AS et al. IRG and GBP host resistance factors target aberrant, non-self vacuoles characterized by the missing of self IRGM proteins. PLoS Pathog 2013;9:e1003414.

Hughes CE, Benson RA, Bedaj M et al. Antigen-presenting cells and antigen presentation in tertiary lymphoid organs. Front Immunol 2016;7, DOI: 10.3389/fimmu.2016.00481.

Hunn JP, Koenen-Waisman S, Papic N et al. Regulatory interactions between IRG resistance GTPases in the cellular response to Toxoplasma gondii. EMBO J 2008;27:2495-509.

Hunter CA, Subauste CS, Van Cleave VH et al. Production of gamma interferon by natural killer cells from Toxoplasma gondii-infected SCID mice: Regulation by interleukin-10, interleukin-12, and tumor necrosis factor alpha. Infect Immun 1994;62:2818-24.

Ince S, Kutsch M, Shydlovskyi S et al. The human guanylate-binding proteins hGBP-1 and hGBP-5 cycle between monomers and dimers only. FEBS J 2017;284:2284-301.

Ince $\mathrm{S}$, Zhang $\mathrm{P}$, Kutsch $\mathrm{M}$ et al. Catalytic activity of human Guanylate-Binding Protein 1 coupled to the release of structural restraints imposed by the C-terminal domain. FEBS J 2020:febs. 15348 .

Ivashkiv LB. IFNy: signalling, epigenetics and roles in immunity, metabolism, disease and cancer immunotherapy. Nat Rev Immunol 2018;18:545-58.

Johnston AC, Piro A, Clough B et al. Human GBP1 does not localize to pathogen vacuoles but restricts Toxoplasma gondii. Cell Microbiol 2016;18:1056-64.

Kim B-H, Shenoy AR, Kumar P et al. A Family of IFN-y-Inducible 65kD GTPases Protects Against Bacterial Infection. Science 2011;332:717-21.

Kohler KM, Kutsch M, Piro AS et al. A rapidly evolving polybasic motif modulates bacterial detection by guanylate binding proteins. MBio 2020;11:1-14.

Krapp C, Hotter D, Gawanbacht A et al. Guanylate Binding Protein (GBP) 5 Is an Interferon-Inducible Inhibitor of HIV-1 Infectivity. Cell Host Microbe 2016;19:504-14.

Kravets E, Degrandi D, Ma Q et al. Guanylate binding proteins directly attack Toxoplasma gondii via supramolecular complexes. Elife 


\section{6;5:e11479.}

Kravets E, Degrandi D, Weidtkamp-Peters $S$ et al. The GTPase activity of murine guanylate-binding protein 2 (mGBP2) controls the intracellular localization and recruitment to the parasitophorous vacuole of Toxoplasma gondii. J Biol Chem 2012;287:27452-66.

Kutsch M, Sistemich L, Lesser CF et al. Direct binding of polymeric GBP1 to LPS disrupts bacterial cell envelope functions. EMBO J 2020:e104926.

Lindenberg $\mathrm{V}$, Mölleken $\mathrm{K}$, Kravets $\mathrm{E}$ et al. Broad recruitment of mGBP family members to Chlamydia trachomatis inclusions. Dean D (ed.). PLoS One 2017;12:e0185273.

Liu BC, Sarhan J, Panda A et al. Constitutive Interferon Maintains GBP Expression Required for Release of Bacterial Components Upstream of Pyroptosis and Anti-DNA Responses. Cell Rep 2018;24:155-168.e5.

MacMicking JD. Interferon-inducible effector mechanisms in cellautonomous immunity. Nat Rev Immunol 2012;12:367-82.

Man SM, Karki R, Malireddi RKS et al. The transcription factor IRF1 and guanylate-binding proteins target activation of the AIM2 inflammasome by Francisella infection. Nat Immunol 2015;16:467475.

Matta SK, Patten K, Wang Q et al. NADPH oxidase and guanylate binding protein 5 restrict survival of avirulent type III strains of Toxoplasma gondii in naive macrophages. MBio 2018;9:01393-18. Meunier E, Dick MS, Dreier RF et al. Caspase-11 activation requires lysis of pathogen-containing vacuoles by IFN-induced GTPases. Nature 2014;509:366-70.

Meunier E, Wallet P, Dreier RF et al. Guanylate-binding proteins promote activation of the AIM2 inflammasome during infection with Francisella novicida. Nat Immunol 2015;16:476-84.

Modiano N, Lu YE, Cresswell P. Golgi targeting of human guanylatebinding protein-1 requires nucleotide binding, isoprenylation, and an IFN-y-inducible cofactor. Proc Natl Acad Sci USA 2005;102:8680-5. Nantais DE, Schwemmle M, Stickney JT et al. Prenylation of an interferon- $\gamma$-induced GTP-binding protein: The human guanylate binding protein, huGBP1. J Leukoc Biol 1996;60:423-31.

Olszewski MA, Gray J, Vestal DJ. In Silico Genomic Analysis of the Human and Murine Guanylate-Binding Protein ( GBP ) Gene Clusters. J Interf Cytokine 2006;352:328-52.

Pappas G, Roussos N, Falagas ME. Toxoplasmosis snapshots: Global status of Toxoplasma gondii seroprevalence and implications for pregnancy and congenital toxoplasmosis. Int $J$ Parasitol 2009;39:1385-94.

Park EK, Jung HS, Yang $\mathrm{HI}$ et al. Optimized THP-1 differentiation is required for the detection of responses to weak stimuli. Inflamm Res 2007;56:45-50.

Piro AS, Hernandez D, Luoma S et al. Detection of Cytosolic Shigella flexneri via a C-Terminal Triple-Arginine Motif of GBP1 Inhibits ActinBased Motility. MBio 2017;8, DOI: 10.1128/mBio.01979-17.

Praefcke GJK, Kloep S, Benscheid U et al. Identification of Residues in the Human Guanylate-binding Protein 1 Critical for Nucleotide Binding and Cooperative GTP Hydrolysis. J Mol Biol 2004;344:25769.

Prakash B, Praefcke GJK, Renault L et al. Structure of human guanylate-binding protein 1 representing a unique class of GTPbinding proteins. Nature 2000;403:567-71.

Qin A, Lai D-H, Liu Q et al. Guanylate-binding protein 1 (GBP1) contributes to the immunity of human mesenchymal stromal cells against Toxoplasma gondii. Proc Natl Acad Sci USA 2017;114:136570.

Remington JS, McLeod R, Wilson CB et al. Toxoplasmosis. Infectious
Diseases of the Foetus and Newborn Infant. 2011, 918-1041.

Roche PA, Furuta K. The ins and outs of MHC class II-mediated antigen processing and presentation. Nat Rev Immunol 2015;15:203-16.

Rosales C, Uribe-Querol E. Phagocytosis: A Fundamental Process in Immunity. Biomed Res Int 2017;2017, DOI: 10.1155/2017/9042851. Ryves WJ, Evans AT, Olivier AR et al. Activation of the PKC-isotypes alpha, beta 1, gamma, delta and epsilon by phorbol esters of different biological activities. FEBS Lett 1991;288:5-9.

Sanjana NE, Shalem O, Zhang F. Improved vectors and genomewide libraries for CRISPR screening. Nat Methods 2014;11:783-4.

Schwemmle M, Staeheli P. The interferon-induced $67-k D a$ guanylatebinding protein (hGBP1) is a GTPase that converts GTP to GMP. $J$ Biol Chem 1994;269:11299-305.

Sibley DL. Invasion and intracellular survival by protozoan parasites. Immunol Rev 2011;240:72-91.

Tedesco S, De Majo F, Kim J et al. Convenience versus Biological Significance: Are PMA-Differentiated THP-1 Cells a Reliable Substitute for Blood-Derived Macrophages When Studying in Vitro Polarization? Front Pharmacol 2018;9:71.

Tretina K, Park E, Maminska A et al. Interferon-induced guanylatebinding proteins: Guardians of host defense in health and disease. $J$ Exp Med 2019:1-19.

Tripal P, Bauer M, Naschberger E et al. Unique features of different members of the human guanylate-binding protein family. $J$ Interf cytokine Res 2007;27:44-52.

Turner MD, Nedjai B, Hurst T et al. Cytokines and chemokines: At the crossroads of cell signalling and inflammatory disease. Biochim Biophys Acta - Mol Cell Res 2014;1843:2563-82.

Uhlen M, Fagerberg L, Hallstrom BM et al. Tissue-based map of the human proteome. Science 2015;347:1260419-1260419.

Virreira Winter S, Niedelman W, Jensen KD et al. Determinants of GBP Recruitment to Toxoplasma gondii Vacuoles and the Parasitic Factors That Control It. Moreno SN (ed.). PLoS One 2011;6:e24434. Wallet $\mathrm{P}$, Benaoudia S, Mosnier A et al. IFN-y extends the immune functions of Guanylate Binding Proteins to inflammasomeindependent antibacterial activities during Francisella novicida infection. PLoS Pathog 2017:1-26.

Wandel MP, Pathe C, Werner El et al. GBPs Inhibit Motility of Shigella flexneri but Are Targeted for Degradation by the Bacterial Ubiquitin Ligase IpaH9.8. Cell Host Microbe 2017;22:507-518.e5.

Wehner M, Herrmann C. Biochemical properties of the human guanylate binding protein 5 and a tumor-specific truncated splice variant. FEBS J 2010;277:1597-605.

Wilgenburg B van, Browne C, Vowles J et al. Efficient, Long Term Production of Monocyte-Derived Macrophages from Human Pluripotent Stem Cells under Partly-Defined and Fully-Defined Conditions. Covas DT (ed.). PLoS One 2013;8:e71098.

Wilson DC, Matthews S, Yap GS. IL-12 Signaling Drives CD8 + T Cell IFN-Y Production and Differentiation of KLRG1 + Effector Subpopulations during Toxoplasma gondii Infection. I Immunol 2008;180:5935-45.

Wynn TA, Chawla A, Pollard JW. Macrophage biology in development, homeostasis and disease. Nature 2013;496:445-55.

Xavier A, Al-Zeer MA, Meyer TF et al. hGBP1 Coordinates Chlamydia Restriction and Inflammasome Activation through Sequential GTP Hydrolysis. Cell Rep 2020;31:107667.

Zwack EE, Feeley EM, Burton AR et al. Guanylate Binding Proteins Regulate Inflammasome Activation in Response to Hyperinjected Yersinia Translocon Components. Infect Immun 2017;85:e00778-16. 


\section{Supplementary Information}

This is supplementary information to the preprint manuscript from Fisch et al. 2021. Supplementary section contains supplementary tables, supplementary figures and figure legends. All further information is available upon request.

\section{Supplementary tables}

Table 1: List of cell lines

\begin{tabular}{|c|c|}
\hline Cells & Source \\
\hline HEK 293T & Cell Services, Crick Institute \\
\hline HFF & ATCC \\
\hline KOLF iPSC & HESCU STP \\
\hline THP-1 & ATCC \\
\hline THP-1 $\triangle G B P 1$ & Fisch et al. 2019a \\
\hline THP-1 $\triangle G B P 1+$ Tet & Fisch et al. 2019a \\
\hline THP-1 $\triangle G B P 1+$ Tet-EV & Fisch et al. 2019a \\
\hline THP-1 $\triangle G B P 1+$ Tet-GBP1 & Fisch et al. 2019a \\
\hline THP-1 $\triangle G B P 1+$ Tet-GBP1 ${ }^{\text {C589A }}$ & Fisch et al. 2019a \\
\hline THP-1 $\triangle G B P 1+$ Tet-GBP1D103L/D108L & This study \\
\hline THP-1 $\triangle G B P 1+$ Tet-GBP1 $1112 A$ & This study \\
\hline THP-1 $\triangle G B P 1+$ Tet-GBP1 ${ }^{\mathrm{D} 184 \mathrm{~N}}$ & This study \\
\hline THP-1 $\triangle G B P 1+$ Tet-GBP1 ${ }^{\mathrm{D} 192 \mathrm{E}}$ & Fisch et al. 2020 \\
\hline THP-1 $\triangle G B P 1+$ Tet-GBP1 ${ }^{E 99 A}$ & This study \\
\hline THP-1 $\triangle G B P 1+$ Tet-GBP1 ${ }^{K 51 A}$ & Fisch et al. 2019a \\
\hline THP-1 $\triangle G B P 1+$ Tet-GBP1 ${ }^{\text {R48A }}$ & This study \\
\hline THP-1 $\triangle G B P 1+T e t-G B P 1^{R 48 P}$ & This study \\
\hline THP-1 $\triangle G B P 1+$ Tet-GBP1 $1^{\text {R584-586A }}$ & This study \\
\hline THP-1 $\triangle G B P 1+$ Tet-GBP1RK227/228EE & Fisch et al. 2019a \\
\hline THP-1 $\triangle G B P 1+T e t-G B P 1^{S 52 N}$ & This study \\
\hline THP-1 $\triangle G B P 1+$ Tet-GBP1 ${ }^{\text {T75A }}$ & This study \\
\hline THP-1 $\triangle G B P 1+$ Tet-GBP1 ${ }^{\triangle 589-592}$ & Fisch et al. 2019a \\
\hline THP-1 $\triangle G B P 1+$ Tet-mCH-GBP1 & Fisch et al. 2019a \\
\hline THP-1 $\triangle G B P 1+$ Tet-mCH-GBP1 ${ }^{\text {C589A }}$ & Fisch et al. 2019a \\
\hline THP-1 $\triangle G B P 1+T e t-m C H-G B P 1$ D103L/D108L & This study \\
\hline THP-1 $\triangle G B P 1+T e t-m C H-G B P 1^{D 112 A}$ & This study \\
\hline THP-1 $\triangle G B P 1+T e t-m C H-G B P 1^{D 192 E}$ & Fisch et al. 2020 \\
\hline THP-1 $\triangle G B P 1+$ Tet-mCH-GBP1K51A & Fisch et al. 2019a \\
\hline THP-1 $\triangle G B P 1+$ Tet-mCH-GBP1R48A & This study \\
\hline THP-1 $\triangle G B P 1+$ Tet-mCH-GBP1 ${ }^{\text {R584-586A }}$ & This study \\
\hline THP-1 $\triangle G B P 1+$ Tet-mCH-GBP1 RK227/228EE & Fisch et al. 2019a \\
\hline THP-1 $\triangle G B P 1+$ Tet-mCH-GBP1 ${ }^{\mathrm{S} 52 \mathrm{~N}}$ & This study \\
\hline THP-1 $\triangle G B P 1+$ Tet-mCH-GBP1 ${ }^{\Delta 589-592}$ & Fisch et al. 2019a \\
\hline THP-1 $\triangle G B P 2$ & This study \\
\hline THP-1 $\triangle G B P 2+$ Tet & This study \\
\hline THP-1 $\triangle G B P 2+$ Tet-EV & This study \\
\hline THP-1 $\triangle G B P 2+$ Tet-GBP2 & This study \\
\hline THP-1 $\triangle G B P 2+$ Tet-GBP2 $2^{\triangle 588-591}$ & This study \\
\hline THP-1 $\triangle G B P 2+$ Tet-GBP2 ${ }^{\mathrm{C} 588 \mathrm{~A}}$ & This study \\
\hline THP-1 $\triangle G B P 2+$ Tet-GBP2 $2^{\mathrm{D} 103 \mathrm{~L} / \mathrm{D} 108 \mathrm{~L}}$ & This study \\
\hline THP-1 $\triangle G B P 2+$ Tet-GBP2 ${ }^{\mathrm{K} 51 \mathrm{~A}}$ & This study \\
\hline THP-1 $\triangle G B P 2+$ Tet-mCH-GBP2 & This study \\
\hline THP-1 $\triangle G B P 2+$ Tet-mCH-GBP2 $2^{\triangle 588-591}$ & This study \\
\hline THP-1 $\triangle G B P 2+T e t-m C H-G B P 2^{C 588 A}$ & This study \\
\hline THP-1 $\triangle G B P 2+T e t-m C H-G B P 2^{D 103 L / D 108 L}$ & This study \\
\hline THP-1 $\triangle G B P 2+$ Tet-mCH-GBP2 $2^{\mathrm{K} 11 \mathrm{~A}}$ & This study \\
\hline THP-1 $\triangle G B P 5$ & Krapp et al, 2016 \\
\hline THP-1 $\triangle G B P 5+$ Tet & This study \\
\hline
\end{tabular}




\begin{tabular}{|c|c|}
\hline Cells & Source \\
\hline THP-1 $\triangle G B P 5+$ Tet-EV & This study \\
\hline THP-1 $\triangle G B P 5+$ Tet-GBP5 & This study \\
\hline THP-1 $\triangle G B P 5+T e t-G B P 5^{\Delta 588-591}$ & This study \\
\hline THP-1 $\triangle G B P 5+$ Tet-GBP5 ${ }^{\mathrm{C} 588 \mathrm{~A}}$ & This study \\
\hline THP-1 $\triangle G B P 5+T e t-G B P 5^{\mathrm{KS} 51 / 52 \mathrm{AA}}$ & This study \\
\hline THP-1 $\triangle G B P 5+$ Tet-mCH-GBP5 & This study \\
\hline THP-1 $\triangle$ GBP5+Tet-mCH-GBP5 $5^{\Delta 588-591}$ & This study \\
\hline THP-1 $\triangle G B P 5+$ Tet-mCH-GBP5 $5^{\mathrm{C} 588 \mathrm{~A}}$ & This study \\
\hline THP-1 $\triangle G B P 5+$ Tet-mCH-GBP5 ${ }^{\mathrm{KS} 51 / 52 \mathrm{AA}}$ & This study \\
\hline
\end{tabular}

\section{Table 2: List of qPCR primers}

\begin{tabular}{|c|c|}
\hline Name & Sequence 5'-3' \\
\hline GBP1-fwd & TATTGCCCACTATGAACAGCAGAT \\
\hline GBP1-rev & TAGCTGGGCCGCTAACTCC \\
\hline GBP2-fwd & AATTAGGGGCCCAGTTGGAAG \\
\hline GBP2-rev & AAGAGACGGTAACCTCCTGGT \\
\hline GBP3-fwd & GAATAAGGGCTTCTCTCTGGGC \\
\hline GBP3-rev & AGTGTCAAGCAGGACTAAGGTG \\
\hline GBP4-fwd & TAAGCGGCTTTCAGAGCACC \\
\hline GBP4-rev & GACCTCGTTTGCCTTAACTCC \\
\hline GBP5-fwd & CCTGATGATGAGCTAGAGCCTG \\
\hline GBP5-rev & GCACCAGGTTCTTTAGACGAGA \\
\hline GBP6-fwd & TGCACCATCCCATTTGTGGAA \\
\hline GBP6-rev & TGCCAACCTAGAAGAGCCTGC \\
\hline GBP7-fwd & GAGTTAAGGCAGACGAGGTCC \\
\hline GBP7-rev & TTCAGCTGCCTCCTTCTTAGC \\
\hline HPRT1-fwd & ACCAGTCAACAGGGGACATAA \\
\hline HPRT1-rev & CTTCGTGGGGTCCTTTTCACC \\
\hline
\end{tabular}

Table 3: List of primary antibodies

IF: immunofluorescence; IB = immunoblotting; FC: flow cytometry

\begin{tabular}{|l|l|l|l|l|l|}
\hline Antibody & IF & IB & FC & Supplier & Cat. number \\
\hline Actin & & $\mathbf{x}$ & & Sigma & A2228 \\
\hline CD14 & & & $\mathbf{x}$ & Biolegend & $\# 325607$ \\
\hline CD16 & & & $\mathbf{x}$ & Biolegend & $\# 302005$ \\
\hline CD68 & & & $\mathbf{x}$ & Biolegend & $\# 137027$ \\
\hline GBP1 $(\mathrm{mAb})$ & $\mathrm{x}$ & $\mathrm{x}$ & & home-made & \\
\hline GBP1 $(\mathrm{pAb})$ & & $\mathrm{x}$ & & home-made & sc-271568 \\
\hline GBP2 & & $\mathrm{x}$ & & santa cruz & $\# 67798$ \\
\hline GBP5 & & $\mathrm{x}$ & & CST & ab52649 \\
\hline GM-130 & $\mathrm{x}$ & & & abcam & ab167453 \\
\hline mCherry & & $\mathbf{x}$ & & abcam & \\
\hline
\end{tabular}


bioRxiv preprint doi: https://doi.org/10.1101/2021.08.24.457560; this version posted August 24, 2021. The copyright holder for this preprint (which was not certified by peer review) is the author/funder, who has granted bioRxiv a license to display the preprint in perpetuity. It is made available under aCC-BY-NC-ND 4.0 International license.

\section{Supplementary Figures}

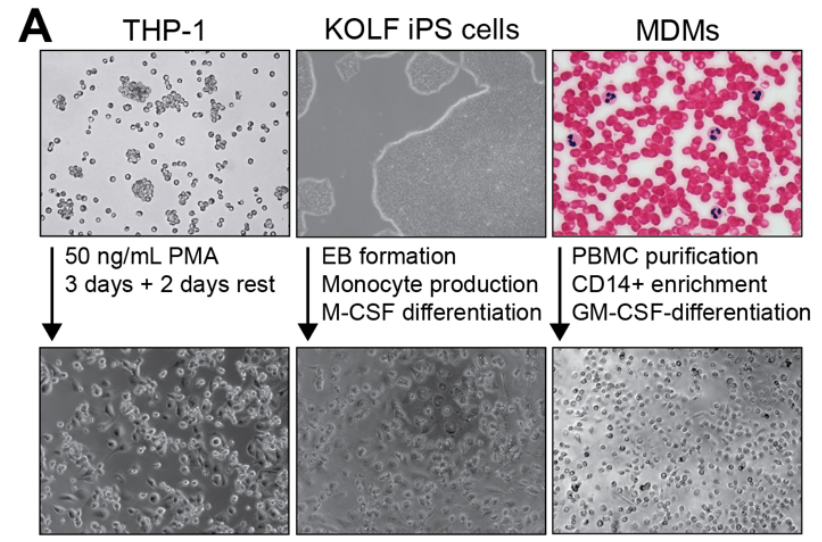

\section{C}

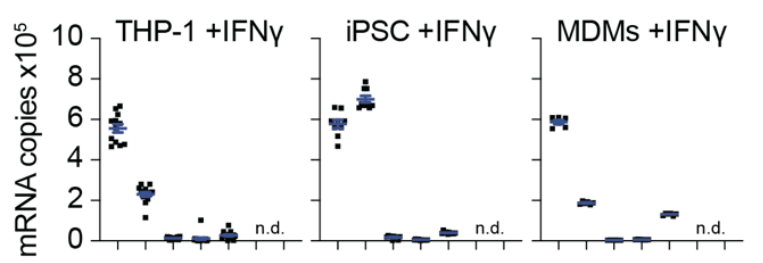

D

THP-1

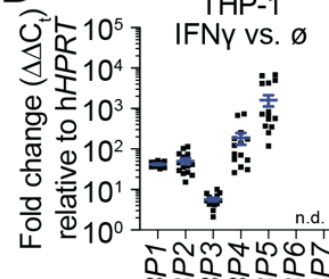

iPSC

IFNY VS. ø

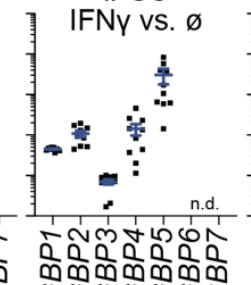

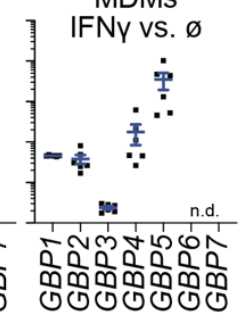

B

THP-1 monocytes $3 \mathrm{~d}$ PMA $+2 \mathrm{~d}$ rest

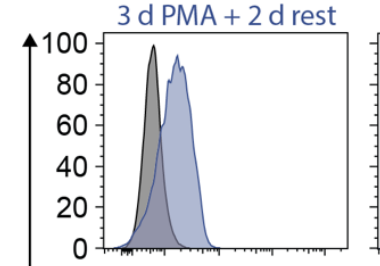

Harvested monocytes $5 \mathrm{~d}$ M-CSF

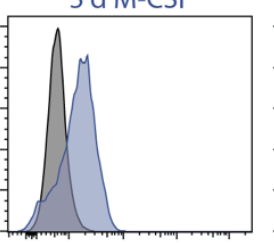

CD14+ PBMCs

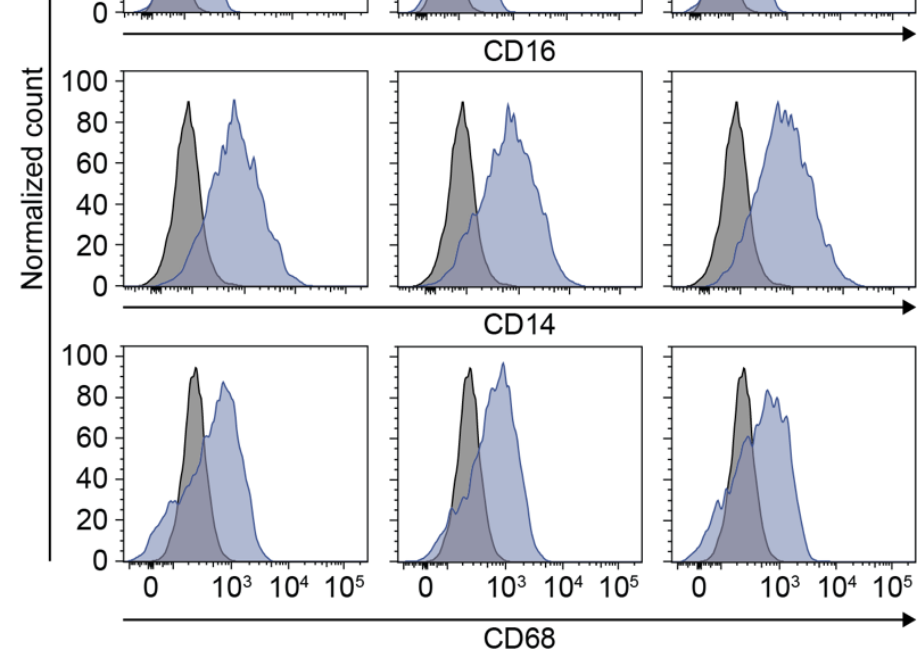

Figure S1: Growth morphology and differentiation of human macrophage models

(A) Images of human macrophage cell lines before (top) and following indicated differentiation steps (bottom). Human induced pluripotent stem cells (iPSC); embryonic body (EB); peripheral blood monocytic cell (PBMC). Scale bar, $50 \mu \mathrm{m}$. Image of whole blood from https://commons.wikimedia.org/. (B) Flow cytometry measuring CD14, CD16 or CD68 surface expression of the indicated cell line, prior to (black) or post differentiation into macrophages (blue). (C) Absolute mRNA copies of indicated GBP per cell for IFNY-primed THP-1, iPSC-derived or monocyte-derived macrophages (MDM) at $16 \mathrm{~h}$ post treatment. (D) Fold change induction of indicated GBP following treatment of indicated cell line with $50 \mathrm{IU} \mathrm{mL}^{-1}$ IFNy for 16 hours, plotted as $\Delta \Delta \mathrm{Ct}$ normalizing to untreated cells $(\varnothing)$ and relative to human Hypoxanthine-guanine phosphoribosyltransferase (HPRT1). Data information: Graphs in (B) representative of $n=3$ independent experiments or $n=4$ different donors (MDMs). Graphs in (C+D) show data from $n=14$ (THP-1) or $n=10$ (iPSC) independent experiments or $n=6$ donors (MDMs) and mean \pm SEM; n.d. not detected. 
bioRxiv preprint doi: https://doi.org/10.1101/2021.08.24.457560; this version posted August 24, 2021. The copyright holder for this preprint (which was not certified by peer review) is the author/funder, who has granted bioRxiv a license to display the preprint in perpetuity. It is made available under aCC-BY-NC-ND 4.0 International license.

A

D

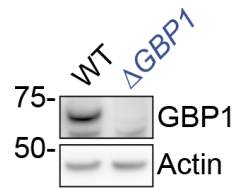

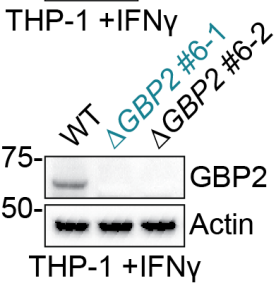

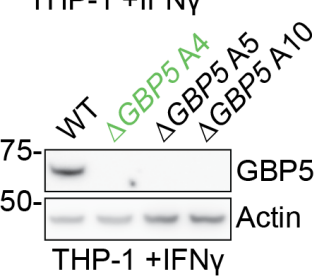

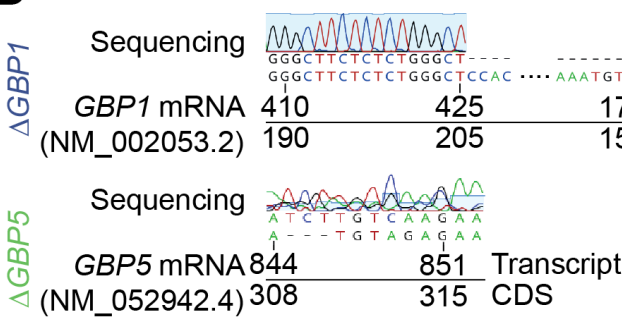

C
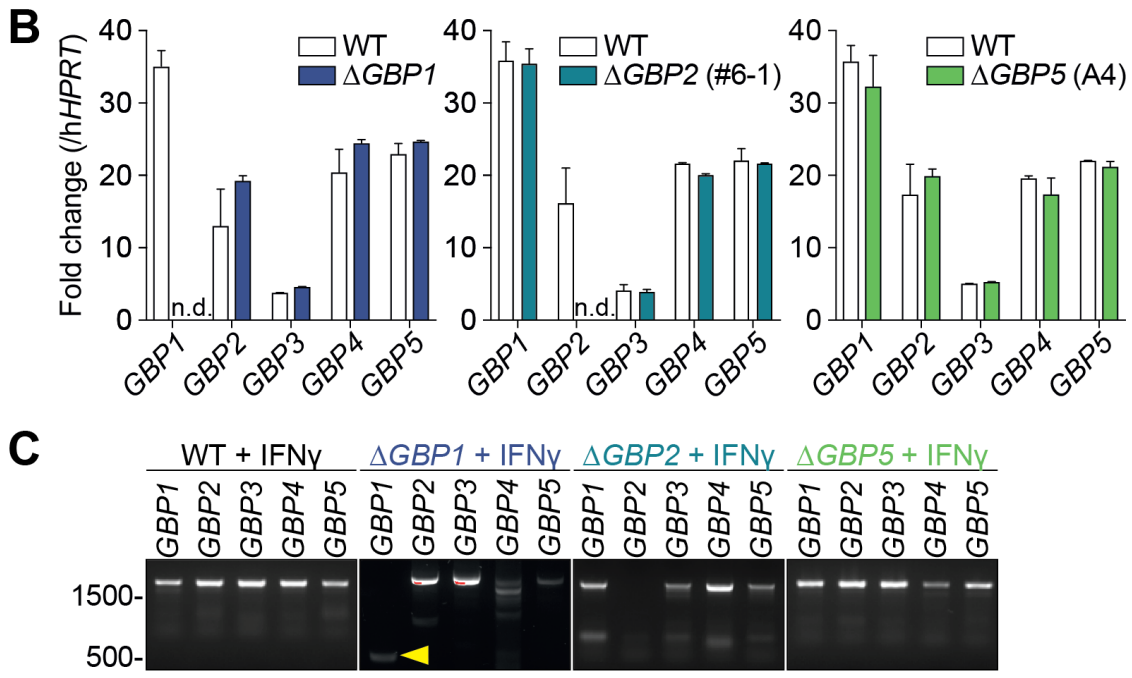

$\mathbf{F}$

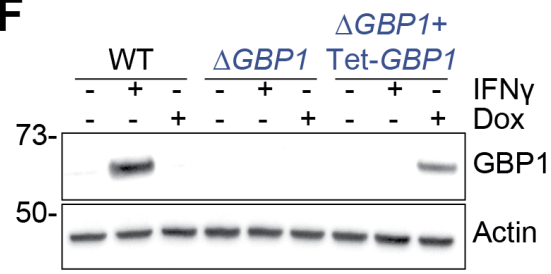

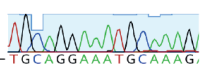
$1737 \quad 1750$ Transcript 1530 CDS

E

\begin{tabular}{|c|c|c|c|}
\hline Gene & $\triangle G B P 1$ & $\triangle G B P 2$ & $\triangle G B P 5$ \\
\hline GBP1 & $\begin{array}{c}\text { Deletion of pos. } \\
426-1736 \text { = deletion after } \\
\text { G68 + frameshift }\end{array}$ & WT & WT \\
\hline GBP2 & WT & n.d. & WT \\
\hline GBP3 & WT & WT & WT \\
\hline GBP4 & WT & WT & WT \\
\hline GBP5 & WT & WT & $\begin{array}{c}\text { Multiple InDels } \\
\text { at pos. 844 }\end{array}$ \\
\hline
\end{tabular}

Figure S2: Characterization of human GBP CRISPR knockout cell lines

(A) Immunoblots for indicated proteins from IFNy-primed THP-1 WT, THP-1 $\triangle G B P 1, \triangle G B P 2$ or $\triangle G B P 5$ cells. (B) Fold change of mRNA expression of indicated human GBP in IFNy-primed THP-1 WT, THP-1 $\triangle G B P 1, \triangle G B P 2$ or $\triangle G B P 5$ cells relative to human Hypoxanthineguanine phosphoribosyltransferase (HPRT1); n.d.: not detected. (C) PCR amplification of indicated GBP coding sequences (CDS) on cDNA created from mRNA obtained from IFNy-primed THP-1 WT, THP-1 $\triangle G B P 1, \triangle G B P 2$ or $\triangle G B P 5$ cells. Yellow arrowhead highlights truncated GBP1 CDS in THP-1 $\triangle G B P 1$ cells. (D) Sanger sequencing of GBP1 and GBP5 CDS captured into TOPO-TA vectors following PCR amplification shown in (C) aligned to displayed wildtype sequence of respective GBP mRNA. (E) Overview of sequencing results of human GBP CDS from THP-1 $\triangle G B P 1, \triangle G B P 2$ or $\triangle G B P 5$ cells; $n$.d. not detected. (F) Immunoblots from THP-1 WT, $\triangle G B P 1, \triangle G B P 1+T e t-$ GBP1, $\triangle G B P 2, \triangle G B P 2+T e t-G B P 2, \triangle G B P 5$ and $\triangle G B P 5+T e t-G B P 5$ cells treated with IFNy, and Doxycycline (Dox) as indicated. Data information: Images in (A), (C) and (D) representative of $n=2$ experiments. Graphs in (B) show mean \pm SEM from $n=3$ independent experiments. Images in (F) representative of $n=3$ independent experiments. 
A
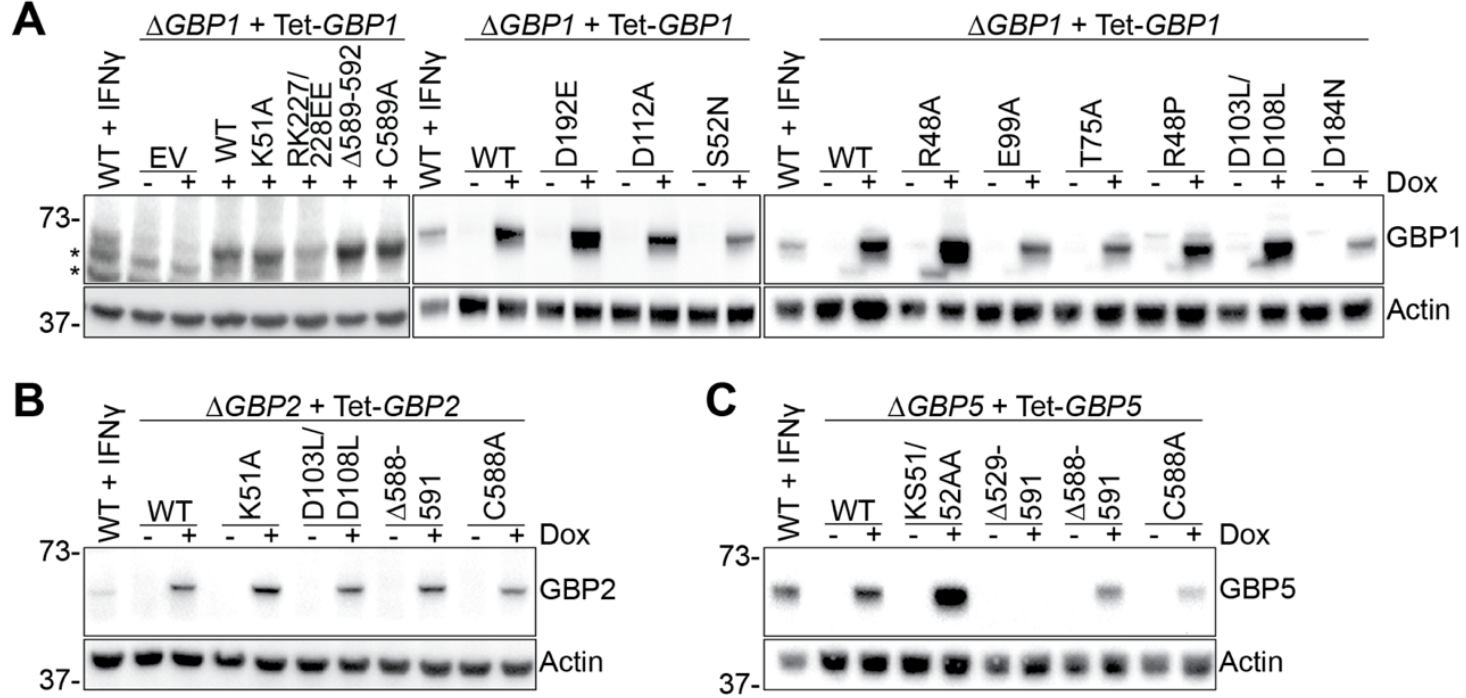

Figure S3: Reconstitution of mutated GBPs into macrophages

Immunoblots from IFNy-primed THP-1 WT and $\triangle G B P 1$ (A), $\triangle G B P 2$ (B) or $\triangle G B P 5$ cells (C) reconstituted with the indicated mutants of GBP1, GBP2 or GBP5 respectively and treated with Doxycycline (Dox) as indicated. *Marks unspecific bands.
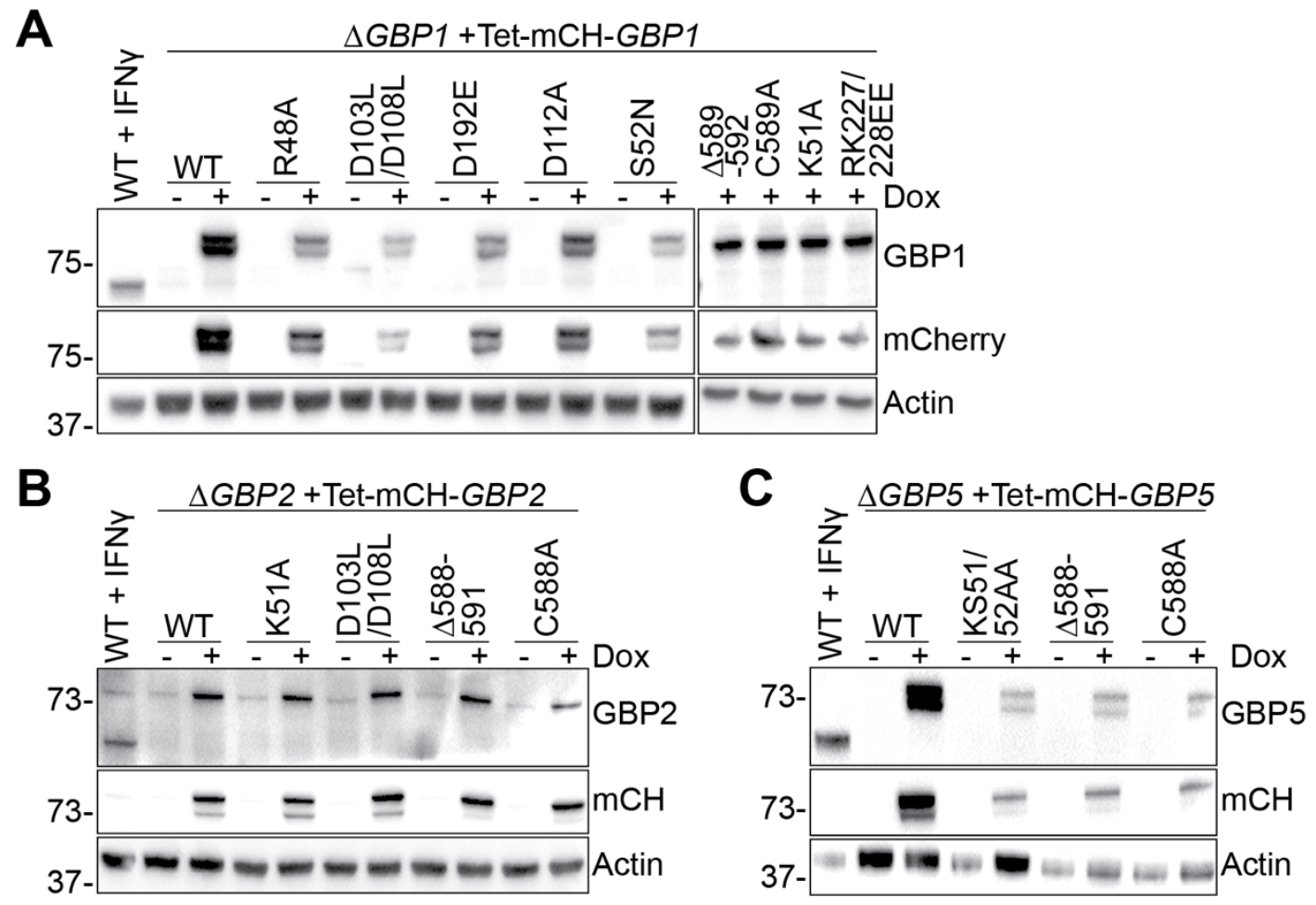

Figure S4: Reconstitution of mutated mCherry-tagged GBPs into macrophages

Immunoblots from IFNy-primed THP-1 WT and $\triangle G B P 1, \triangle G B P 2$ or $\triangle G B P 5$ cells reconstituted with the indicated $\mathrm{mCherry}(\mathrm{mCH})$-tagged mutants of GBP1, GBP2 or GBP5 respectively and treated with Doxycycline (Dox) as indicated. 